\title{
Experimental design approach for development of novel microemulsion system and immediate release self microemulsifying tablet of nebivolol $\mathrm{HCl}$
}

\author{
Hemangi Ramesh Trivedi ${ }^{\circledR 1^{*}}$, Tanvi Mukund Siriah ${ }^{1}$, Prashant Keshao Puranik ${ }^{1}$ \\ ${ }^{1}$ Department of Pharmaceutical Sciences, Rashtrasant Tukadoji Maharaj Nagpur University Campus, Nagpur, India
}

\begin{abstract}
The objective of this study was to determine specific combination of pharmaceutical excipients that lead to formulation of efficient nebivolol hydrochloride SMEDDS and its subsequent formulation into IR-SET (Immediate release- Self emulsifying tablet) which will enhance its solubility and dissolution. Solubility and Pseudo-ternary phase studies were carried out to identify the excipients showing highest solubility and to identify the zone of microemulsion with selected ingredients. Liquid-SMEDDS (L-SMEDDS) were optimized for Concentration of oil(X1) and Smix(X2) and formulated using a combination of Kollisolv GTA as oil, Tween 80 as surfactant and propylene glycol as co-surfactant which gave smaller droplet size(Y1) 55.98nm, Emulsification time (Y2) $16 \pm 1.5 \mathrm{~s}, \%$ transmittance (Y3) $99.94 \pm 0.47 \%$. Neusilin US2 was used as solid carrier for solidification of L-SMEDDS in to Solid-SMEDDS (S-SMEDDS) by adsorption technique. IR-SET of nebivolol were formulated with S-SMEDDS and optimized for the concentration of binder (X1) (PVP K30) and superdisintegrant (X2) (KOLLIDON CL) which showed low Disintegration time (Y1) $(92 \pm 0.5 \mathrm{~s})$ and low Friability(Y2) $(0.424 \pm 0.03 \%)$. Also the DSC and XRD data revealed the molecular state of the drug in S-SMEDDS. The extent of in-vivo drug release and ex-vivo diffusion values from L-SMEDDS and IR-SET was much higher than pure drug and marketed tablet. In conclusion, the results showed potential of SMEDDS to improve solubility and thus the bioavailability.
\end{abstract}

Keywords: Nebivolol hydrochloride. Liquid \& Solid SMEDDS. Full factorial design. Neusilin US2 IR-SET.

\section{INTRODUCTION}

Nebivolol $\mathrm{HCl}$ (NEB) is an oral, highly selective third generation $\beta_{1}$-receptor antagonist, having nitric oxide enhancing vasodilator effect, indicated for the treatment of hypertension. NEB is the newer drug among those $\beta 1$-Adrenergic blockers and also used as monotherapy for initial management of uncomplicated hypertension (Thadkala, Sailu, Aukunuru, 2015). Also NEB has reduced typical beta-blocker related side effects such as fatigue, clinical depression, bradycardia, and impotence (Narkhede, Gujar, Gambhire, 2014). After oral administration of NEB, the peak plasma concentration reaches within $0.5-2 \mathrm{~h}$. Oral bioavailability of NEB is $12 \%$ only because of first pass hepatic metabolism caused by

\footnotetext{
*Correspondence: H. R. Trivedi. Department of Pharmaceutical Sciences, Rashtrasant Tukadoji Maharaj Nagpur University, Mahatma Jyotiba Phuley Education Campus, Amravati Road Campus, Nagpur (Maharashtra), India - 440033. Phone: + 917709017862 / Fax + 91 0712-2500355. E-mail: hemangirtrivedi@gmail.com
}

cytochrome P450 2D6 (CYP2D6) enzymes. It has suitable $\log \mathrm{P}$ (octanol/water) of 4.03 and the recommended daily dose is $5 \mathrm{mg}$ (Vijayanand, Patil, Reddy, 2015).The drug is highly lipophilic belonging to the class BCS II, having low dissolution velocity and bioavailability (Narkhede, Gujar, Gambhire, 2014). The bioavailability can be increased by increasing its solubility and reducing first pass metabolism. Studies have shown that the solubility and stability of lipophilic compounds can be increased by incorporating them into microemulsion based delivery systems due to their small droplet size and kinetic stability (Jaiswal et al., 2014).

Self-microemulsifying drug delivery systems(SMEDDS), one among the lipid-based dosage forms are proven to be promising in improving the oral bioavailability of drug by enhancing solubility, permeability and avoiding first-pass metabolism via enhanced lymphatic transport (Mahajan et al., 2011). SMEDDS are contemplated as isotropic mixtures of a drug, oil, surfactant, and a cosurfactant (Gurram et al., 
2015). The fundamental basis of a SMEDDS system lies in its potential of forming oil-in-water $(\mathrm{o} / \mathrm{w})$ microemulsions with slight agitation and dilution with aqueous phases. The impromptu formation of this micro-emulsion in the gastrointestinal tract dispenses the drug in a more solubilized form, and a large surface area is provided by the small size of the formed droplet for drug absorption. Moreover there is increase in bioavailability due to the presence of lipid in the formulation (Narkhede, Gujar, Gambhire, 2014).

Various efforts have been made to develop effective delivery systems to improve water solubility and bioavailability of NEB including preparation of liquidsoid compact (Pravala, Nagabandi, Ajmeera, 2013), solid dispersions (Shah, Bhatt, Yadav, 2014), nanoparticulate delivery (Jana et al., 2014), oral nanoemulsion (Thadkala, Sailu, Aukunuru, 2015), orodispersible (Vijayanand, Patil, Reddy, 2015) and immediate release tablets (Khalaf et al., 2015).

Self-emulsification has been shown to be specific to the nature of the oil/surfactant pair; the surfactant concentration and oil/surfactant ratio; and the temperature at which self-emulsification occurs. Only very specific pharmaceutical excipients combinations lead to efficient self-emulsifying systems (Rahman et al., 2013; Zanchetta, Chaud, Santana, 2015). However, scanty work is reported on the use of different oil/surfactant/co-surfactant and adsorbent in the preparation of NEB SMEDDS and its subsequent design in immediate release tablet formulation. Hence, in the present study an attempt was made toward the use of different oils, surfactants and co-surfactants for the preparation of L-SMEDDS and use of different adsorbents for preparing solid SMEDDS, IR-SET and their optimization and evaluation.

\section{MATERIAL AND METHODS}

\section{Material}

NEB was procured as a gift sample from Emcure Pharmaceutical Ltd. Pune. Kollisolv GTA(Triacetin), Kollisolv IPM(Isopropyl myristate), MCT 70(Medium chain triglyceride), Solutol HS 15(Polyoxyl 15 hydroxystearate), KOLLIDON CL (Polyvinylpyrrolidone crosslinked) were provided by BASF, Mumbai as a gift sample. Acrysol EL 135(Polyoxyl 35- hydrogenated castor oil) and Acrysol K 140(Polyoxyl 40- hydrogenated castor oil) were kindly gifted by Corel Pharma Ltd. Ahemdabad. Neusilin US2 (Magnesium aluminum silicate) was acquired as a gift sample from Fuji Chemicals, Japan. While Aerosil 200 (Silicon dioxide) was gifted by Evonik
Pvt. Ltd. Mumbai. All other chemicals used for study were of analytical grades.

\section{Methods}

\section{Preformulation studies}

Melting point of NEB was determined using Thiele tube method (Furniss et al., 2008). The analytical method development was done using UV spectroscopic analysis. Calibration plot of NEB was performed in methanol, hydrochloric acid buffer $\mathrm{pH} 1.2$ and phosphate buffer $\mathrm{pH} 7.4$ (PBS). A standard stock solution of $100 \mu \mathrm{g} / \mathrm{mL}$ was prepared, and from this different concentrations in the range of $20-100 \mu \mathrm{g} / \mathrm{mL}$ solution were prepared and used to determine the $\lambda \max$ and calibration curves (Thula, Patel, Maheshwari, 2015). Various validation parameters like linearity, interday precision, intraday precision, robustness, ruggedness, limit of detection, limit of quantitation and \% recovery/accuracy study were determined in accordance with the ICH guidelines (Thula, Patel, Maheshwari, 2015). Characterization of NEB was done by obtaining FT-IR spectra using Shimadzu-IRAFFINITY-1 FT-IR spectrophotometer. The thermal behaviour of the drug was evaluated using differential scanning calorimeter and the enthalpy and melting point range was determined (Vijayanand, Patil, Reddy, 2015).

\section{Solubility studies - selection of SMEDDS components}

\section{Selection of oil}

Solubility of NEB was checked in different oils, surfactants and cosurfactants. $2 \mathrm{~mL}$ of various oils, surfactants, and co-surfactants were taken individually in small vial and surplus drug (100 mg) was added to each vial. The vials were tightly sealed and then heated at $40^{\circ} \mathrm{C}$ in water bath for further solubilisation (Vijayanand, Patil, Reddy, 2015). The mixtures were then sonicated for 15 minutes and stirred steadily for $72 \mathrm{~h}$ with mechanical shaker for proper mixing. Once the mixtures reached equilibrium the contents of all vials were centrifuged at 10,000 rpm for 30 minutes (Remi C-24 plus, India). Aliquot of sample was taken and diluted with methanol at specific volume to give specific point concentration in calibration curve. Analysis of the drug was carried out on double beam UV-Visible spectrophotometer at $650 \mathrm{~nm}$ by placing a blank. The quantification was done according to calibration curve and column graphs were plotted taking solubility in $\mathrm{mg}$ per $\mathrm{mL}$ as ordinate axis (Prajapati, Joshi, Patel, 2013). 


\section{Selection of surfactant}

The criteria for selecting surfactant depended on its ability to emulsify the selected oil phase. To evaluate the emulsification ability, surfactant was added to the selected oil phase, blended thoroughly and then this mixture was diluted with distilled water. The ease of formation of emulsion was monitored by the number inversions of volumetric flask required to produce uniform emulsion. The emulsion was allowed to stand for $2 \mathrm{~h}$ and its transmittance was measured. Emulsion was further monitored for any turbidity or phase separation (Prajapati, Joshi, Patel, 2013).

\section{Selection of co-surfactant}

Co-surfactants were assessed for their influence over the selected surfactants, so as to improve the emulsification capability of the surfactants. For which, a mixture of surfactant and co-surfactant was prepared at a ratio of $2: 1$. To this mixture was added the oil phase and then gently heated in a water bath for proper mixing. This mixture was then diluted with distilled water and observed for the number of inversions required to produce uniform emulsion. Transmittance was measured after the emulsion was allowed to stand for $2 \mathrm{~h}$ (Prajapati, Joshi, Patel, 2013).

\section{Drug excipients compatibility studies}

\section{FTIR Studies}

FTIR - 8001 spectrophotometer (Shimadzu, Japan) was used to obtain spectra of NEB in the isotropic mixtures of excipients. Analysis of pure NEB, NEB with Kollisolv GTA, Tween 80 and Propylene glycol (L-SMEDDS) \& SMEDDS loaded Neusilin US2, Avicel PH102, PVP K30, KOLLIDON CL (IR-SET) were recorded by KBR pellet method. The spectrum was recorded over the frequency range of 4000 to $400 \mathrm{~cm}^{-1}$ and screened for appearance or disappearance of any peak (Patela et al., 2010).

\section{DSC studies}

DSC thermograph of pure NEB, NEB with Kollisolv GTA, Tween 80 and Propylene glycol (L-SMEDDS) \& SMEDDS loaded Neusilin US2, Avicel PH102, PVP K30, KOLLIDON CL (IR-SET) were recorded on differential scanning calorimeter. Thermograms were matched for appearance or disappearance of any peak (Patela et al., 2010).

\section{Pseudo-ternary phase diagram}

Pseudo-ternary phase diagrams were plotted for the excipients selected from solubility and emulsification studies to evaluate the boundaries of the micro emulsion domains. Water titration method was used to plot pseudoternary phase diagram of oil, Smix (surfactant/cosurfactant mixture) and doubled distilled water. Various weight ratios of Smix were selected as 1:1, 1:2, 2:1, 1:3 and $3: 1$. For all pseudo-ternary phase plots, at a specific Smix weight ratio, the mixtures of oil-surfactant-cosurfactant were prepared with the weight ratio of oil to the Smix at $9: 1,8: 2,7: 3,6: 4,5: 5,4: 6,3: 7,2: 8$, and $1: 9$ respectively. To the resultant mixtures, water was added drop wise along with proper stirring, the first sign of clarity in mixture indicate the end point. The point indicating the clear and isotropic mixtures were considered to be within the micro emulsion. The pseudo-ternary phase plots were then constructed by monitoring the mixtures visually, using a software - CHEMIX. The ratio of Smix showing largest micro emulsion zone was selected. Moreover, to analyze the effects of NEB on the emulsifying performance of SMEDDS, the formulation quantity of NEB was added to the boundary formulations of the self-emulsifying domain of the pseudo-ternary phase plots (Rao et al., 2013).

\section{Formulation and optimization of NEB loaded L-SMEDDS by experimental design}

A $3^{2}$ full factorial design measures the response of every possible combination of factors and factor levels and thus suitable for optimizing SMEDDS. It analyzes every response to provide information about main effect and interaction effect. NEB loaded L-SMEDDS were formulated by adding the weighed amount of oil into a screw-capped glass vial and melting it at $40{ }^{\circ} \mathrm{C}$ water bath. To this mixture, surfactant and co-surfactant were added and stirred with a magnetic stirrer. The mixture was then further sonicated for 15 minutes and stored at room temperature until their use in subsequent studies. Based on the data available from the pseudo-ternary phase diagram, two independent variables, namely the concentration of oil $\left(\mathrm{X}_{1}\right)$ as well as the concentration of the $\operatorname{Smix}\left(\mathrm{X}_{2}\right)$ were recognized as important factors responsible for the characteristics of L-SMEDDS, while the droplet size $\left(\mathrm{Y}_{1}\right)$, emulsification time $\left(\mathrm{Y}_{2}\right)$ and percent transmittance $\left(\mathrm{Y}_{3}\right)$ were selected as dependent variables for obtaining the optimized liquid SMEDDS as shown in Table I. A total of 9 batches were prepared and evaluated for droplet size, emulsification time and percent transmittance.

This data was statistically analyzed and validated by Design Expert (Version 8.0.0, Stat-Ease Inc., Minneapolis, $\mathrm{MN})$. ANOVA tables were generated and P-values less than 0.05 were considered to be statistically significant. Various 3-D response surface graphs and contour 
plots were studied for understanding the effect of both formulation variables (Pimple, Yeole, Chaudhari, 2013). The polynomial equation was obtained for droplet size, emulsification time and percent transmittance time using Design Expert software.

$$
\mathrm{Y}=\mathrm{b}_{0}+\mathrm{b}_{1} \mathrm{X}_{1}+\mathrm{b}_{2} \mathrm{X}_{2}+\mathrm{b}_{12} \mathrm{X}_{1} \mathrm{X}_{2}+\mathrm{b}_{11} \mathrm{X}_{1}^{2}+\mathrm{b}_{22} \mathrm{X}_{2}^{2}
$$

where $\mathrm{Y}$ is dependent variable, $\mathrm{b}_{0}$ is the arithmetic mean response of the nine runs and $b_{i}\left(b_{1}-b_{22}\right)$ is the approximate coefficient for the correlated factor $\mathrm{X}_{\mathrm{i}}$ $\left(\mathrm{X}_{1}-\mathrm{X}_{22}\right)$. The interaction term $\left(\mathrm{X}_{1} \mathrm{X}_{2}\right)$ shows the changes in the response when two factors are concurrently changed and the polynomial terms $\left(\mathrm{X}_{1}^{2}\right.$ and $\left.\mathrm{X}_{2}^{2}\right)$ are incorporated to determine nonlinearity. The validity of the developed polynomial equation was verified using design check point analysis.

\section{Evaluation of L-SMEDDS}

\section{Self emulsification time analysis and percent transmittance}

USP dissolution apparatus II was used to determine the emulsification time of SMEDDS. For this, $1 \mathrm{~mL}$ of formulation was added in a drop wise manner at $37 \pm 0.5^{\circ} \mathrm{C}$ to $500 \mathrm{~mL}$ of distilled water. Slight agitation was supplied by dissolution paddle rotating at $50 \mathrm{rpm}$. Time required for emulsification time was observed visually (Khan et al., 2012). Further the sample was subjected to percent transmittance analysis using double beam UV-Visible spectrophotometer using distilled water as blank at wavelength of $650 \mathrm{~nm}$ (Rao et al., 2013).

Droplet size analysis and Zeta potential determination

Photon correlation spectroscopy using NANOPHOX (NX0088) was employed to determine the droplet size of the prepared formulation. Mean droplet size and polydispersity index was determined by diluting $1 \mathrm{~mL}$ of formulation with double distilled water (Rao et al., 2013). Similarly zeta potential of the prepared formulation was determined by Malvern Zetasizer 3000HS (Pandey, Kohli, 2017).

\section{Drug loading capacity}

Drug loading capacity of SMEDDS mixture was determined by taking $2 \mathrm{~mL}$ of optimized SMEDDS in small vial with excess amount of the drug $(100 \mathrm{mg})$. The vial was tightly sealed and for further solubilization, the mixture was heated in water bath at $40{ }^{\circ} \mathrm{C}$. Mixing of the system was performed using sonicator for 15 minutes and was stirred continuously for $72 \mathrm{~h}$ using mechanical shaker. After reaching equilibrium, the content of vial was centrifuged at 10,000 rpm for 30 minutes. Aliquot of sample was taken and diluted with methanol to specific volume to give specific point concentration in calibration curve (Akhildevi et al., 2016).

\section{Cloud point determination}

The temperature at which there is appearance of cloudiness in the formulation is called as cloud point. For cloud point determination the formulation was diluted with distilled water in the ratio of 1:250 and then placed in a water bath with the temperature gradually increasing at $2{ }^{\circ} \mathrm{C}$ intervals (Pandey, Kohli, 2017).

\section{Phase separation study}

SMEDDS were diluted to 50, 100, and 1,000 times with various dissolution media, i.e., water, acid buffer pH 1.2 and phosphate saline buffer $\mathrm{pH}$ 7.4. The diluted micro emulsions were stored for $12 \mathrm{~h}$ and monitored visually for any signs of phase separation or drug precipitation (Rao et al., 2013).

TABLE I - Dependent and independent variables in experimental design used for optimization of L-SMEDDS \& IR-SET

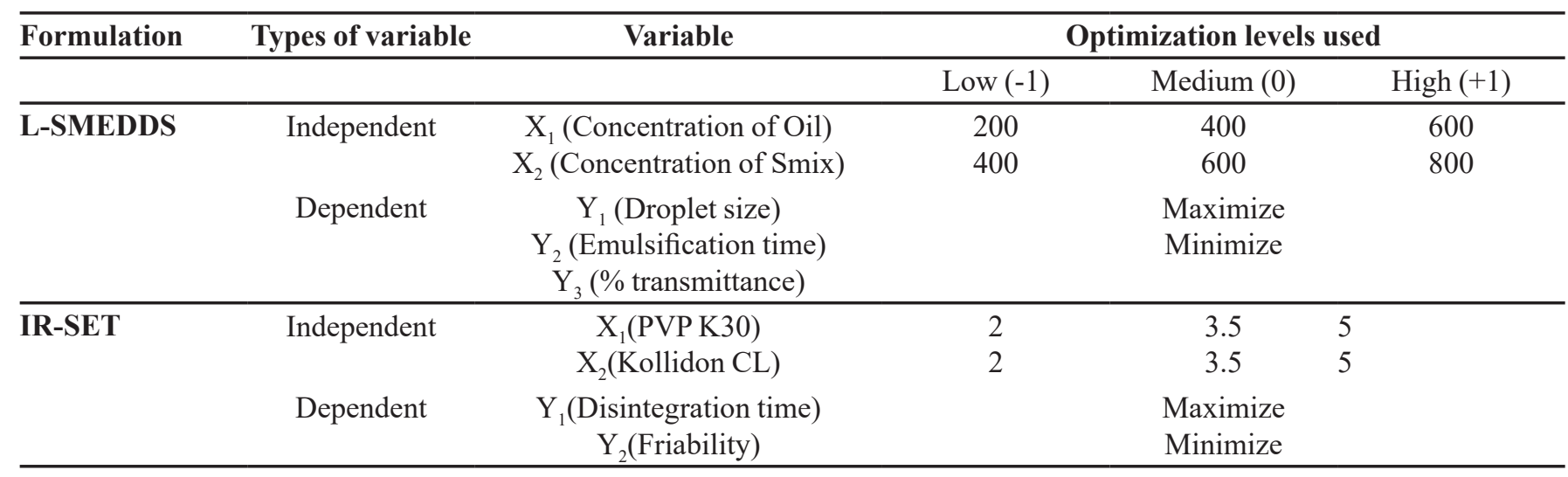




\section{Thermodynamic stability}

Physical stability is crucial for efficiency of a lipid based formulation. Thermodynamic stability studies consist of three phases. Phase I is the heating and cooling cycle where formulation undergoes six heating and cooling cycles, carried out at temperature $40^{\circ} \mathrm{C}$ and $4{ }^{\circ} \mathrm{C}$ and stored for not less than $48 \mathrm{~h}$ at each temperature. After completion of the cycle, the formulation is centrifuged (Phase II) at $5000 \mathrm{rpm}$ for a period of 30 minutes. It was then checked for any physical instability like phase separation, creaming or cracking. Formulation which passed Phase I and II is then subjected to 3 freeze-thaw cycles (Phase III), which comprised of freezing the formulation at $-4{ }^{\circ} \mathrm{C}$ for $48 \mathrm{~h}$ followed by thawing it at $40{ }^{\circ} \mathrm{C}$ for $48 \mathrm{~h}$. Formulation passing these entire three tests is considered as stable formulation (Rao et al., 2013).

\section{Drug content}

The drug content of L-SMEDDS formulation was determined by placing SMEDDS equivalent to dose of drug in $10 \mathrm{~mL}$ volumetric flask and diluted with methanol. The flask was then subjected to sonication for 30 minutes. Necessary dilution was made with methanol. The solution was then filtered through whatman filter paper and analyzed spectrophotometrically (Rao et al., 2013).

\section{Preparation of Solid NEB SMEDDS}

Solid NEB SMEDDS were prepared by mixing L-SMEDDS containing NEB with adsorbent in particular proportion. In brief L-SMEDDS were added drop wise over adsorbent contained in small mortar. After each addition, mixture was homogenized using pestle to ensure uniform distribution of formulation. The obtained damp mass was then passed through sieve and air dried at ambient temperature and stored until further use.

\section{Selection of adsorbent for S-SMEDDS}

S-SMEDDS of individual adsorbent like Neusilin US2, Aerosil 200, microcrystalline cellulose PH102 and lactose were prepared by adsorption onto carrier technique. The prepared S-SMEDDS were further evaluated for flow properties, compressibility index and characterized by Scanning electron microscopy and X-ray diffraction study (Laddha, Suthar, Butani, 2014).

\section{Formulation of immediate release self emulsifying tablet (IR-SET)}

\section{Selection of super-disintegrant}

In order to achieve IR-SET of NEB, superdisintegrants like Croscarmellose sodium, Sodium starch glycolate and KOLLIDON CL were studied by preparing their preliminary batches. The disintegration time was observed as a response.

\section{Formulation and optimization of NEB IR-SET using factorial design}

IR-SET of NEB was formulated by direct compression technique. For this, NEB containing S-SMEDDS and other excipients were accurately weighed, passed through sieve 22 and blended for 15 minutes. To this blend was added magnesium stearate which was previously passed through sieve 60 . This mixture was then compressed into tablets weighing $450 \mathrm{mg}$ using 10 station rotary tablet compression machine with $10.0 \mathrm{~mm}$ flat round punches (Chamunda Pharma Machinery Pvt. Ltd. Ahmedabad) (Ahammad, Pani, 2016).

A $3^{2}$ full factorial design was selected to study the effect of the independent variables i.e. Concentration of PVP K30 $\left(\mathrm{X}_{1}\right)$ and Concentration of KOLLIDON CL $\left(\mathrm{X}_{2}\right)$ on the dependent variables - Disintegration time and Friability. The approximate levels of these independent variables were chosen from results of preliminary batches and are given in Table I. Statistical analysis was carried out for the obtained data, and was further validated by Design Expert (Version 8.0.0, Stat-Ease Inc., Minneapolis, $\mathrm{MN})$. Various 3-D response surface graphs and contour plots were studied to study the effect of the formulation variables (Porter et al., 2008).

ANOVA tables were generated and P-values less than 0.05 were considered to be statistically significant. The polynomial equation was obtained for disintegration time and friability using Design Expert software.

$$
\mathrm{Y}=\mathrm{b}_{0}+\mathrm{b}_{1} \mathrm{X}_{1}+\mathrm{b}_{2} \mathrm{X}_{2}
$$

where $\mathrm{Y}$ is the dependent variable, $\mathrm{b}_{0}$ is the arithmetic mean response of the nine runs and $b_{i}\left(b_{1}\right.$ and $\left.b_{2}\right)$ is the approximate coefficient for the correlated factor $\mathrm{X}_{\mathrm{i}}\left(\mathrm{X}_{1}\right.$ and $\mathrm{X}_{2}$ ). The validity of the developed polynomial equation was verified using design check point analysis.

\section{Evaluation of NEB IR-SET}

NEB IR SET tablets were evaluated for various parameters namely hardness, $\%$ friability, in vitro disintegration time, turbidity measurement and percent transmittance, Droplet size analysis and polydispersity index, zeta potential, drug content, dissolution studies and stability testing. Hardness of tablets $(n=3)$ was estimated by Monsanto hardness tester. Friability was estimated 
using Roche friabilator (Veego scientific, India). Tablets $(n=6)$ from every batch were selected randomly, weighed and placed in the plastic chamber provided in apparatus. Friabilator was operated for 100 revolutions and tablets were collected, de-dusted and reweighed. Percent friability was determined by the difference obtained in two weights. The in vitro disintegration test was done in accordance with USP. The emulsion layer was separated as supernatant from adsorbed solid components present in tablets by centrifuging the medium containing disintegrated tablets at $1000 \mathrm{rpm}$ for $3 \mathrm{~min}$. The obtained emulsion was then further analyzed for droplet size and turbidity measurement. While the other parameters were evaluated by the same procedure as given under the evaluation of L-SMEDDS (Ahammad, Pani, 2016).

\section{In-vitro drug release}

In-vitro drug dissolution study was performed for L-SMEDDS, IR-SET, Plain drug and Marketed tablets using USP dissolution apparatus II. Test conditions for dissolution were $900 \mathrm{~mL}$ of dissolution medium i.e. $\mathrm{HCl}$ buffer $\mathrm{pH} 1.2$., with a rotating speed of $50 \mathrm{rpm}$ and temperature $37 \pm 0.5^{\circ} \mathrm{C}$. During the study, $10 \mathrm{~mL}$ of the aliquots were removed at predetermined time intervals $(10,20,30,40,50$, and 60 minutes) from the dissolution medium and replaced with fresh medium. The amount of NEB released in the dissolution medium was determined spectrophotometrically (Rao et al., 2013).

\section{Ex-vivo release profile}

For ex-vivo study, stomach of previously sacrificed Male Sprague-Dawley rat was isolated and thoroughly washed with phosphate saline buffer $\mathrm{pH} 7.4$ to remove the mucous and lumen contents. NEB loaded formulations (L-SMEDDS/IR-SET/Plain drug/Marketed tablets) were diluted/dispersed separately with $\mathrm{HCl}$ buffer $\mathrm{pH} 1.2$ and filled in the stomach. Both the ends of the tissues were tied properly to avoid any leakage and were placed into beaker containing $50 \mathrm{~mL}$ of phosphate saline buffer $\mathrm{pH} 7.4$ as the diffusion medium with the continuous aeration supply under gentle stirring at $37 \pm 2{ }^{\circ} \mathrm{C}$. Samples were drawn from the medium at specific time intervals and were evaluated by spectrophotometric analysis (Vijayanand, Patil, Reddy, 2015).

\section{Stability study}

A short term stability study of NEB L-SMEDDS and NEB IR-SET was performed for three months for which the glass vial was filled with optimized L-SMEDDS and placed in stability chambers at $40{ }^{\circ} \mathrm{C} / 75 \% \mathrm{RH}$. Formulation was removed at each time point ( 0 day, 1 month, 2 month and 3 month) and evaluated for self emulsification time, drug content and $\%$ drug release in 10 minutes and percent friability (Kamble et al., 2012).

\section{RESULTS AND DISCUSSION}

\section{Preformulation studies}

The melting point range was found to be $228-230^{\circ} \mathrm{C}$ by Thiele tube method which met the criteria. The $\lambda \max$ of NEB was found to be $282 \mathrm{~nm}$ in methanol. Figure 1 shows the regression equation and correlation coefficient for calibration in methanol, $\mathrm{pH} 1.2 \mathrm{HCl}$ buffer and $\mathrm{pH}$ 7.4 PBS. The regression equation for all the solvents followed Lambert-Beer's law and a linear relationship was depicted by the correlation coefficient which was found to be near 1 .The linearity range was $20-100 \mu \mathrm{g} / \mathrm{mL}$. The $\%$ RSD values for intra-day and inter-day validation parameters were found to be 0.6260 and 0.4210 . While the $\%$ RSD values for robustness and ruggedness were found to be 0.2890 and 0.2732 . The percent recovery for 20,30 and $40 \mu \mathrm{g} / \mathrm{mL}$ solutions were found to be 99.037 , 98.210, and $95.340 \%$ respectively. The Limit of Detection (LOD) and limit of quantification (LOQ) for $10 \mu \mathrm{g} / \mathrm{mL}$ was found to be 0.5202 and 0.0663 respectively. The validation study confirms adequate sample stability and method reliability over a period of $24 \mathrm{~h}$ as the selected concentration lies within linearity range and observed RSD was less than $2 \%$. The FT-IR spectrum of NEB exhibited characteristic peaks (Figure 2A) while the DSC graph of NEB displayed a sharp endothermic peak at $233.3{ }^{\circ} \mathrm{C}$ corresponding to its melting point and indicating its crystalline nature(Figure $3 \mathrm{~A}$ ).

\section{Solubility studies - selection of L-SMEDDS components}

\section{Selection of oil}

The goal of the solubility study was to identify a suitable oily phase for the development of the NEB SMEDDS. The oil having the maximal solubilizing potential will be selected in order to achieve optimum drug loading (Prajapati, Joshi, Patel, 2013). The solubility values of NEB in various oils, surfactants and cosurfactants are given in Table II. Among the various oils that were screened, Kollisolv IPM and Kollisolv GTA showed maximum solubility because of their hydrophilic nature, as compared to others $(12.41 \pm 1.31 \mathrm{mg} / \mathrm{mL} \&$ 
$7.98 \pm 1.08 \mathrm{mg} / \mathrm{mL}$ respectively) (BASF, 2012, 2013). While the selection of the surfactant and cosurfactant in

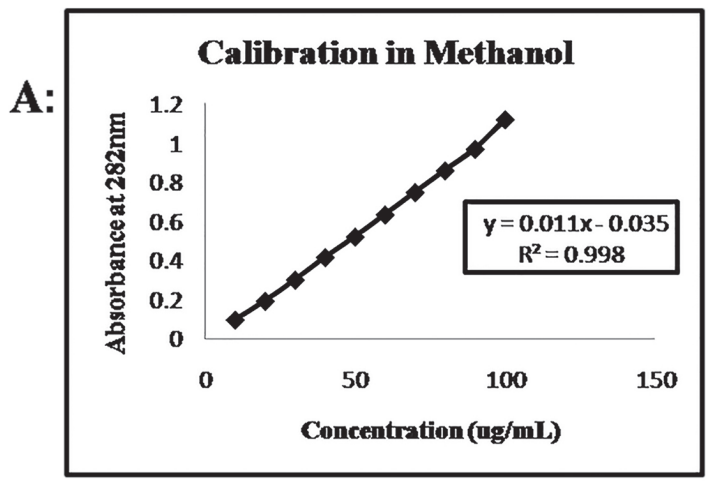

the further study was determined by their emulsification efficiency.
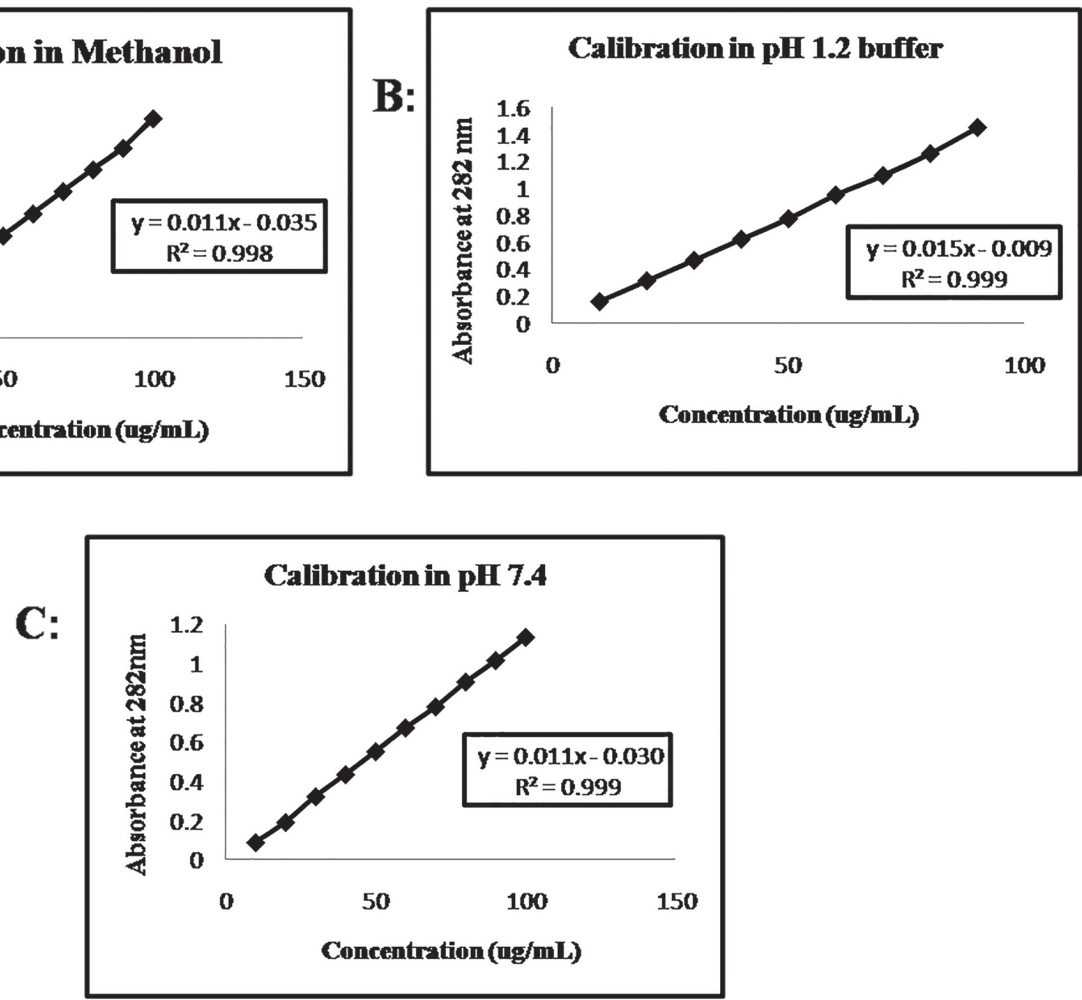

FIGURE 1 - Calibration curve of NEB in (A) Methanol, (B) pH $1.2 \mathrm{HCl}$ buffer, (c) Phosphate buffer pH 7.4.
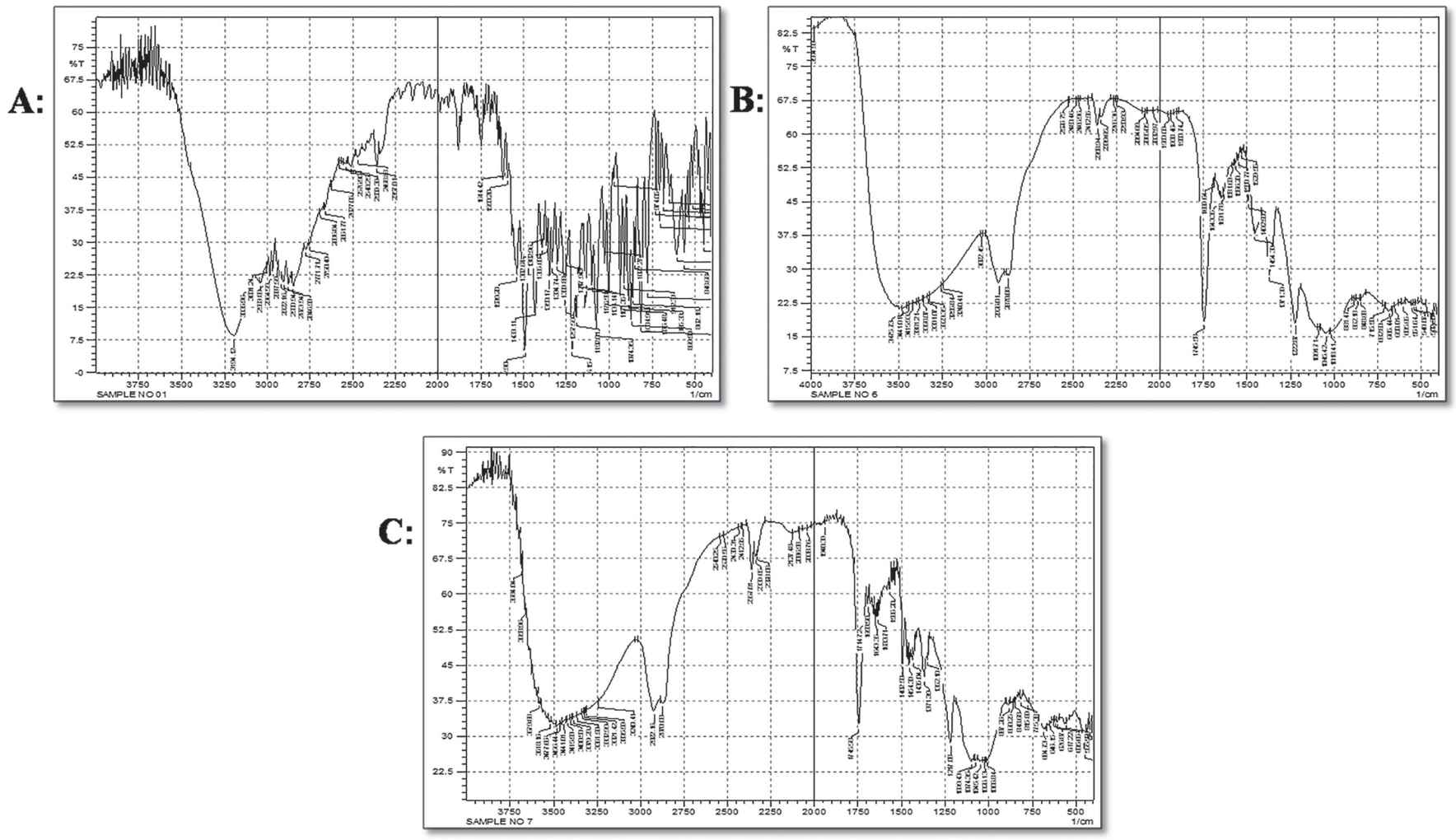

FIGURE 2 - FTIR spectra of (A) Nebivolol HCl (B) L-SMEDDS (C) IR-SET. 

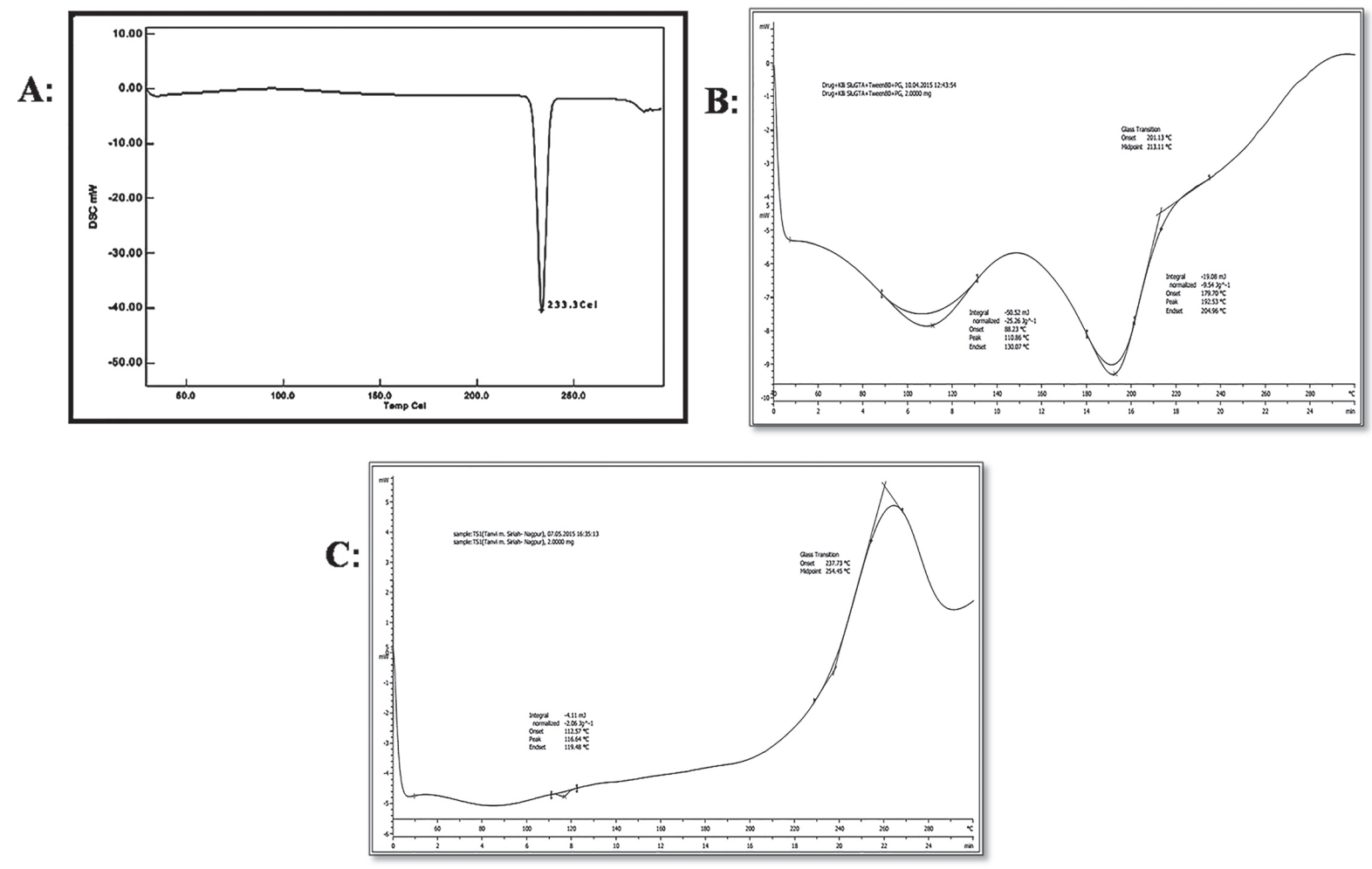

FIGURE 3 - DSC thermograms of (A) Nebivolol HCl (B) L-SMEDDS (C) IR-SET.

\section{Selection of surfactants}

Nonionic surfactants are used for oral ingestion as they are considered less toxic that ionic surfactants (Porter et al., 2008). Thus based on solubility studies

TABLE II - Solubility of NEB in various excipients

\begin{tabular}{lc}
\hline Excipients & Solubility $(\mathbf{m g} / \mathbf{m L})$ \\
\hline Oils & \\
Castor Oil & $1.23 \pm 0.20$ \\
Soyabean Oil & $0.44 \pm 0.01$ \\
Kollisolv GTA & $7.98 \pm 1.89$ \\
Kollisolv IPM & $12.41 \pm 1.31$ \\
MCT 70 & $0.89 \pm 0.23$ \\
\hline Surfactants & \\
Span 80 & $10.45 \pm 2.31$ \\
Tween 80 & $13.33 \pm 0.77$ \\
Acrysol EL 135 & $10.76 \pm 1.09$ \\
Solutol HS & $7.19 \pm 0.45$ \\
Acrysol K 140 & $12.53 \pm 0.31$ \\
\hline Cosurfactants & \\
PEG 200 & $18.74 \pm 0.57$ \\
PEG 400 & $7.55 \pm 0.61$ \\
Propylene glycol & $25.87 \pm 1.05$ \\
Iso propyl alcohol & $0.98 \pm 0.03$ \\
\hline
\end{tabular}

Kollisolv GTA, Kollisolv IPM, and Castor oil: Acrysol K 140 were selected as oil phases and Acrysol K 140, Acrysol EL 135, Tween 80 and Span 80 were selected as surfactants. The emulsification efficiency of surfactants was determined and the results are given in Table III. From the surfactant emulsification test, Kollisolv GTA showed good emulsification efficiency with all surfactants and highest $\%$ transmittance of about $99.613 \%$ with Tween 80 .Whereas, Kollisolv IPM in spite of having highest solubility, its emulsification efficiency was poor and hence Kollisolv GTA \& Tween 80 were selected as oil and surfactant, respectively for further studies.

\section{Selection of co-surfactant}

Based on solubility studies, PEG 400, PEG 200 and Propylene Glycol were selected as co-surfactants. The emulsification efficiency with Kollisolv GTA as oil and Tween 80 as surfactant was performed and the results (Table IV) showed that Propylene glycol gave highest $\%$ transmittance of $99.57 \%$ because of being water soluble (Madan, Sudarshan, Kadam, 2014) and hence was selected as co-surfactant for further studies.

\section{Drug excipients compatibility studies}

\section{FTIR studies}

The FT-IR spectrum of NEB exhibited a sharp peak 
Experimental design approach for development of novel microemulsion system

TABLE III - Emusification efficiency of oil with different surfactants

\begin{tabular}{lccc}
\hline Oil & Surfactant & Appearance & \% Transmittance \\
\hline Kollisolv IPM & Acrysol K 140 & Hazy bluish transparent & 76.4553 \\
& Acrysol EL 135 & Hazy + Milky & 53.7765 \\
& Tween 80 & Hazy bluish transparent & 93.5831 \\
& Span 80 & Hazy bluish transparent + precipitate & 10.518 \\
\hline Kollisolv GTA & Acrysol K 140 & Clear transparent & 99.1441 \\
& Acrysol EL 135 & Clear transparent & 98.6482 \\
& Tween 80 & Clear transparent & 99.6139 \\
& Span 80 & Hazy bluish transparent + precipitate & 77.348 \\
\hline Castor oil: Acrysol K 140 & Acrysol K 140 & Hazy bluish transparent & 93.0874 \\
& Acrysol EL 135 & Clear transparent & 98.4155 \\
& Tween 80 & Hazy bluish transparent & 87.0026 \\
& Span 80 & Hazy Milky & 51.3911 \\
\hline
\end{tabular}

TABLE IV - Emulsification efficiency of Kollisolv GTA -Tween 80 with different co-surfactants

\begin{tabular}{lccc}
\hline Oil/Surfactant & Co-surfactants & Appearance & \% Transmittance \\
\hline Kollisolv GTA/Tween 80 & PEG 200 & Clear transparent & 98.1737 \\
Kollisolv GTA/Tween 80 & PEG 400 & Clear transparent & 98.9188 \\
Kollisolv GTA/Tween80 & Propylene glycol & Clear transparent & $\mathbf{9 9 . 5 7 0 8}$ \\
\hline
\end{tabular}

of $\mathrm{OH}$ group at $3194.12 \mathrm{~cm}^{-1}$. It showed aromatic C-H and C-C stretch at $2964.85 \mathrm{~cm}^{-1}$ and $1750.00 \mathrm{~cm}^{-1}$ respectively. The principal IR absorption peaks of NEB were observed in the L-SMEDDS and IR-SET spectrums. The spectrums of L-SMEDDS and IR-SET showed non-significant changes in the absorption peak of $\mathrm{OH}$ stretching of $\mathrm{NEB}$ from $3194.12 \mathrm{~cm}^{-1}$ to $3381.21 \mathrm{~cm}^{-1}$ and $3379.29 \mathrm{~cm}^{-1}$ respectively (Figure 2). These spectral observations thus indicated no interaction between the NEB and the excipients (Narkhede, Gujar, Gambhire, 2014).

\section{DSC studies}

NEB displayed a sharp endothermic peak at $233.3{ }^{\circ} \mathrm{C}$. The thermogram of L-SMMEDS exhibited a diffused peak instead of a sharp endothermic peak demonstrating that the drug might be in a molecularly dissolved state in L-SMEDDS (Figure 3). While Optimized IR-SET showed the disappearance of endothermic peak which indicates the presence of drug in molecularly dissolved state (Figure 3). Hence, it can be concluded that there is no interaction of drugs with excipients and they are compatible (Narkhede, Gujar, Gambhire, 2014).

\section{Pseudoternary phase diagram}

Pseudo-ternary phase diagrams were formulated without NEB to determine the self emulsifying regions and obtain the concentration range of excipients for the microemulsion region. A chain of SMEDDSs were prepared and visually observed for their self-emulsifying properties. The pseudo-ternary phase diagrams were constructed for each system using CHEMIX software shown in Figure 4. It was discovered that as the concentration of the surfactant with respect to co-surfactant increases in SMEDDS formulation, the spontaneity of the self-emulsification region decreases. The maximum micro emulsion zone was shown at the Smix ratio of 1:2 as compared to others. Hence, surfactant: co-surfactant ratio (1:2) was selected for the formulation. Moreover similar phase diagram was obtained when constructed in the presence of NEB (Figure 4F) (Khan et al., 2012).

\section{Formulation and Optimization of NEB loaded L-SMEDDS by Experimental design}

The $3^{2}$ factorial design was constructed for the optimization of NEB loaded L-SMEDDS. The 9 experimental runs with actual values of independent variables and observed response parameters i.e. Droplet size $\left(\mathrm{Y}_{1}\right)$, Emulsification time $\left(\mathrm{Y}_{2}\right)$ and Percent transmittance $\left(\mathrm{Y}_{3}\right)$ are shown in Table $\mathrm{V}$. Very wide variation is observed in the droplet size and self emulsification time and little variation in $\%$ transmittance on changing the composition of formulation. The droplet size, self emulsification time 
A:

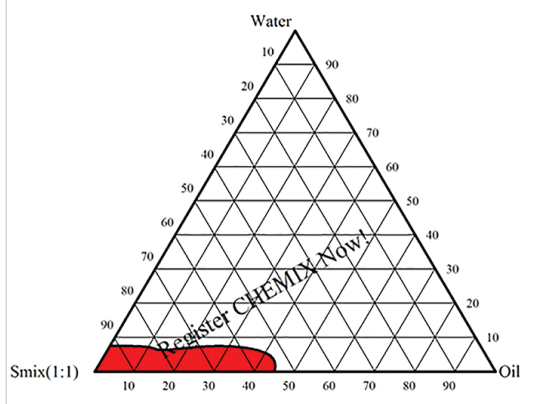

D:

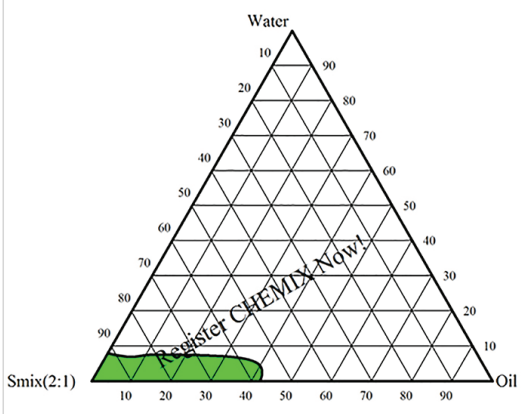

B:

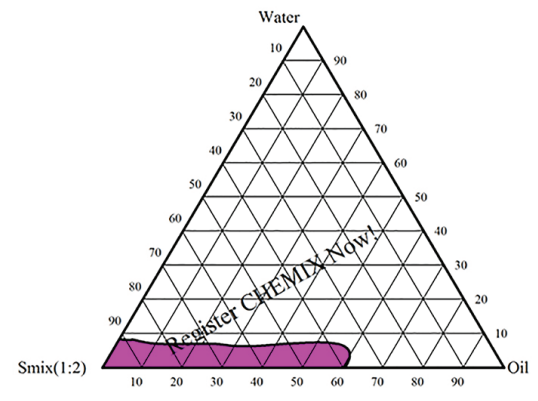

E:

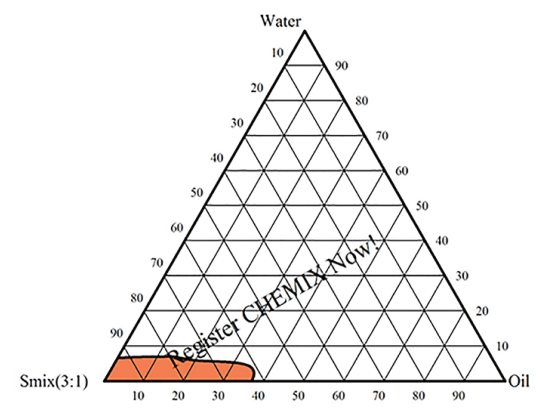

C:

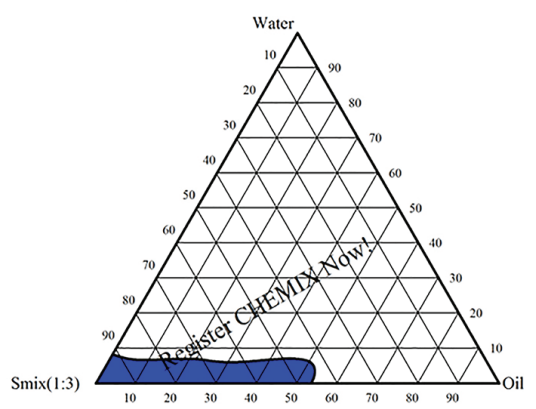

F:

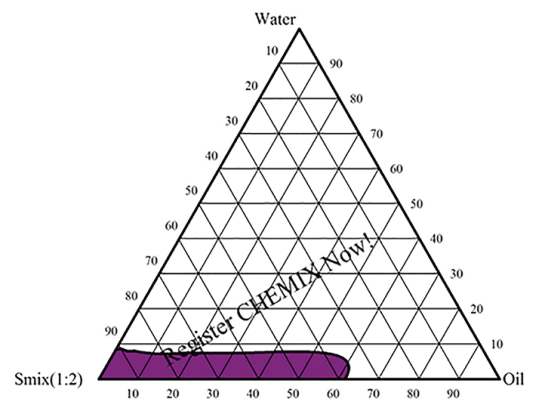

FIGURE 4 - Pseudo-ternary phase diagram of (A) Smix (1:1), (B) Smix (1:2), (C) Smix (1:3), (D) Smix (2:1), (E) Smix (3:1), (F) $\operatorname{Smix}(1: 2)$ with drug.

and $\%$ transmittance ranged from $55.98 \mathrm{~nm}$ to $203.6 \mathrm{~nm}$, $16 \pm 1.52 \mathrm{~s}$ to $103 \pm 2.51 \mathrm{~s}$, and $94.14 \pm 0.45$ to $99.94 \pm 0.47$, respectively (Table V). Batch F3 shows smallest droplet size $(55.98 \mathrm{~nm})$, minimum self emulsification time $(16 \pm 1.52 \mathrm{~s})$ and highest $\%$ transmittance $(99.94 \%)$ and was selected for further processing.

Statistical analysis was carried out for all nine formulation batches by Design-Expert Software (Version 8.0.7.1, Stat-EaseInc., Minneapolis, MN). The effect of independent variables can be explained based upon the following equations:

(Droplet size) $\mathrm{Y}_{1}=120.22+39.38 \mathrm{X}_{1}-20.18 \mathrm{X}_{2}$ (Emulsification time) $\mathrm{Y}_{2}=54.56+26.17 \mathrm{X}_{1}-17.83 \mathrm{X}_{2}$ (Percent transmittance) $\mathrm{Y}_{3}=98.61+0.053 \mathrm{X}_{1}+1.75 \mathrm{X}_{2}-$ $1.24 \mathrm{X}_{1} \mathrm{X}_{2}+0.41 \mathrm{X}_{1}^{2}-1.56 \mathrm{X}_{2}^{2}$

Statistical significant coefficients $(\mathrm{P}=0.0165$ and $\mathrm{F}$ value $=8.79$ for $Y_{1}, P=0.0170$ and $F$ value $=8.66$ for $Y_{2}$ while for $Y_{3} P=0.0294$ and $F$ value $=13.27$ ) were obtained for the model. From the $\mathrm{P}$ and $\mathrm{F}$ values, it could be concluded that the independent variables i.e. concentration of oil $\left(\mathrm{X}_{1}\right)$ and concentration of $\operatorname{Smix}\left(\mathrm{X}_{2}\right)$ significantly affect the responses. The positive coefficient of $\mathrm{X}_{1} \& \mathrm{X}_{2}$ indicates that the response is favored while the negative value indicates an inverse relationship between the factor and the response. The equations exhibit that as the concentration of oil $\left(\mathrm{X}_{1}\right)$ increases droplet size and emulsification time increases while as concentration of $\operatorname{Smix}\left(\mathrm{X}_{2}\right)$ increases droplet size and emulsification time decreases. On the other hand both the factors have positive relationship on Percent transmittance $\left(\mathrm{Y}_{3}\right)$ (Akhildevi et al., 2016).

The check point formulation (NEB L-SMEDDS) was based on the optimum process variables and desired responses. The concentration of oil $\left(\mathrm{X}_{1}\right)$ and concentration of $\operatorname{Smix}\left(\mathrm{X}_{2}\right)$ chosen were $200 \mathrm{mg}$ and $770 \mathrm{mg}$ respectively. The Droplet size $\left(\mathrm{Y}_{1}\right)$, Emulsification time $\left(\mathrm{Y}_{2}\right)$ and Percent transmittance $\left(\mathrm{Y}_{3}\right)$, predicted and experimental results are summarized in Table VI. The predicted value was compared with experimental value by calculating percentage error $(0.61 \%)$ which was found to be quite low, proved validity of generated model in predicting response. The similarity between experimental and predicted values indicated the validity of the generated model. The contour plots and 3D response curves were obtained as shown in Figure 5. 3D figures showed linear ascending pattern for droplet size, emulsification time and percent transmittance with increasing concentration of Smix.

\section{Evaluation of L-SMEDDS}

\section{Self emulsification time analysis and percent} transmittance

Self emulsification time analysis is an important 
TABLE V - Optimization of L-SMEDDS using Factorial design

\begin{tabular}{lccccc}
\hline Batches & $\begin{array}{c}\mathbf{X}_{1} \\
\text { Conc. of Oil } \\
(\mathbf{m g})\end{array}$ & $\begin{array}{c}\mathbf{X}_{2} \\
\text { Conc. of Smix } \\
(\mathbf{m g})\end{array}$ & $\begin{array}{c}\mathbf{Y}_{1} \\
\text { Droplet size } \\
(\mathbf{n m})\end{array}$ & $\begin{array}{c}\mathbf{Y}_{2} \\
\text { Emulsification time } \\
(\mathbf{s e c})\end{array}$ & $\begin{array}{c}\mathbf{Y}_{3} \\
\text { \% Transmittance } \\
(\mathbf{\%})\end{array}$ \\
\hline F1 & 200 & 400 & 117.57 & $29 \pm 2.08$ & $94.14 \pm 0.45$ \\
F2 & 200 & 600 & 71.91 & $22 \pm 3.01$ & $99.71 \pm 0.26$ \\
F3 & 200 & 800 & 55.98 & $16 \pm 1.52$ & $99.94 \pm 0.47$ \\
F4 & 400 & 400 & 136.91 & $76 \pm 2.08$ & $95.26 \pm 0.36$ \\
F5 & 400 & 600 & 91.6 & $92 \pm 2.00$ & $98.32 \pm 0.41$ \\
F6 & 400 & 800 & 126.3 & $32 \pm 3.05$ & $99.13 \pm 0.38$ \\
F7 & 600 & 400 & 203.6 & $103 \pm 2.51$ & $97.32 \pm 0.21$ \\
F8 & 600 & 600 & 123.4 & $68 \pm 1.46$ & $98.63 \pm 0.42$ \\
F9 & 600 & 800 & 154.71 & $53 \pm 2.42$ & $98.16 \pm 0.33$ \\
\hline
\end{tabular}

TABLE VI - Experimental and predicted values of the optimized batch

\begin{tabular}{lccc}
\hline Formulation & & \multicolumn{2}{c}{ Responses } \\
\cline { 3 - 4 } & & Predicted & Experimental \\
\hline L-SMEDDS & Droplet size (nm) & 60.6633 & 55.98 \\
(Batch F3) & Emulsification time (sec) & 10.5556 & $16 \pm 1.52$ \\
& \% Transmittance (\%) & 100.401 & $99.94 \pm 0.47$ \\
\hline IR-SET & Disintegration time (sec) & 97.7222 & $92 \pm 0.57$ \\
(Batch B9) & Friability (\%) & 0.428944 & $0.424 \pm 0.03$ \\
\hline
\end{tabular}

parameter for determining the emulsification efficiency i.e. SMEDDS should quickly disperse under mild agitation. The self emulsification time for the optimized batch (F3) was $16 \pm 1.52 \mathrm{~s}$ and the percent transmittance at wavelength of $650 \mathrm{~nm}$ was found out to be $99.94 \pm 0.47 \%$ indicating low particle size.

\section{Droplet size analysis and polydispersity index}

The smaller droplet size of the micro emulsion indicates more rapid absorption and improved bioavailability of drug. Results displayed that as the concentration of Smix increases the mean droplet size decreases. The optimized formula (F3) showed $55.98 \mathrm{~nm}$ droplet size and 0.37 polydispersity index. Figure $6 \mathrm{~A}$ depicts the distribution of droplet size in optimized formula. While the stability of the emulsion was determined by zeta potential as it directs the degree of repulsion between similarly charged, adjacent, dispersed droplets. The zeta potential value depending on a specific system being used, if reduced below a certain value leads to flocculation or instability (Bakhle, Avari, 2015). The zeta potential of the optimized formula (F3) was found to be $-26.8 \mathrm{mV}$, indicating the stable micro emulsion (Figure 6C).

\section{Drug loading capacity}

Drug loading capacity of optimized batch (F3) containing Kollisolv GTA, Tween 80 and Propylene glycol was found to be $17.6420 \pm 0.09 \mathrm{mg} / \mathrm{g}$.

\section{Cloud point determination}

Cloud point is the temperature point at which there is a sudden impression of turbidity appearing in the formulation visually (Jaiswal et al., 2014). Hence this study assists in determining the performance of developed SMEDDS formulation at body temperature. Cloud point of optimized formula (F3) was found to be $85^{\circ} \mathrm{C}$, which indicates that micro emulsion will be stable at physiological temperature without risk of phase separation.

\section{Phase separation study}

Dilution may better mimic conditions in the stomach following oral administration of SMEDDS preconcentrate. Dilution study was done to determine the effect of dilution on SMEDDS pre-concentrates. After diluting SMEDDS to 50, 100 and 1000 times with water, acid buffer $\mathrm{pH} 1.2$ and phosphate saline buffer $\mathrm{pH} 7.4$ and 


\section{Design-Expert@ Software
Factor Coding: Actual}

A: Droplet Size

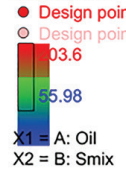

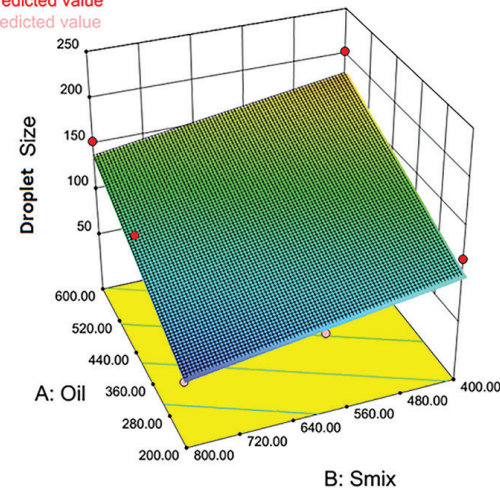

Design-Expert@ Software

Factor Coding: Actual

B: Emulsification Time

- Design points above predicted value

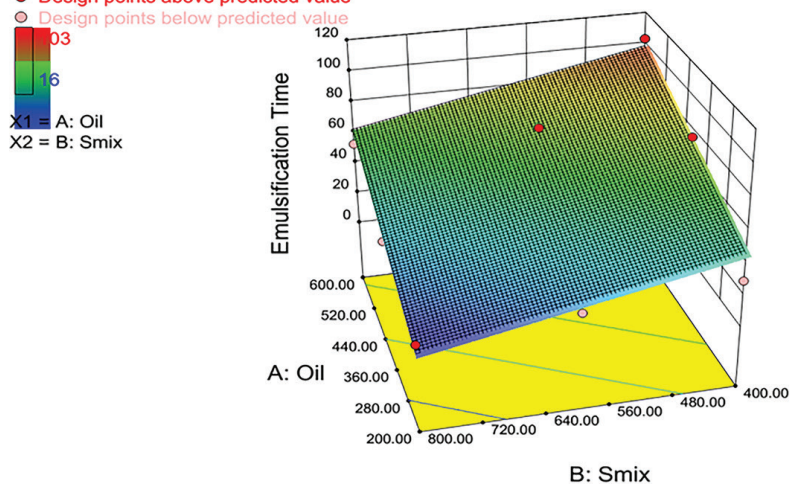

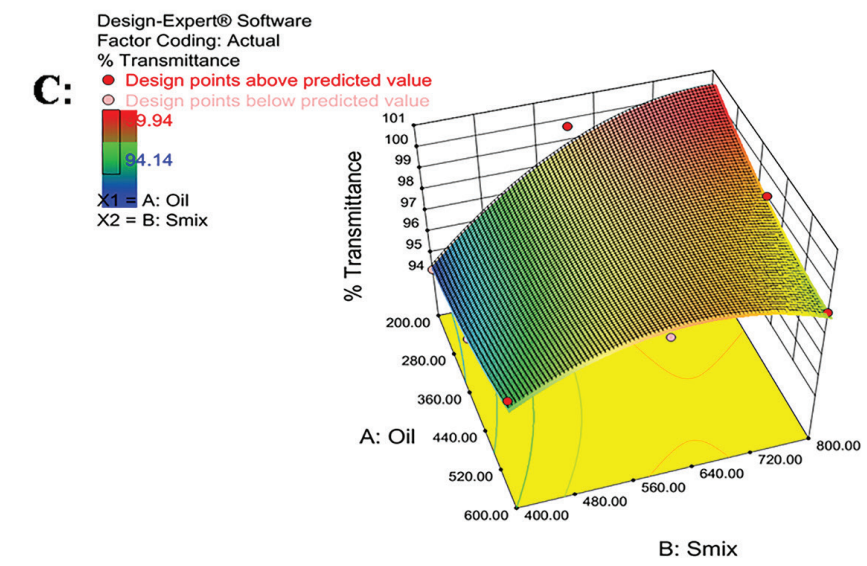

FIGURE 5 - Response surface plot for (A) Droplet size (B) Emulsification time (C) Percent transmittance.

A:

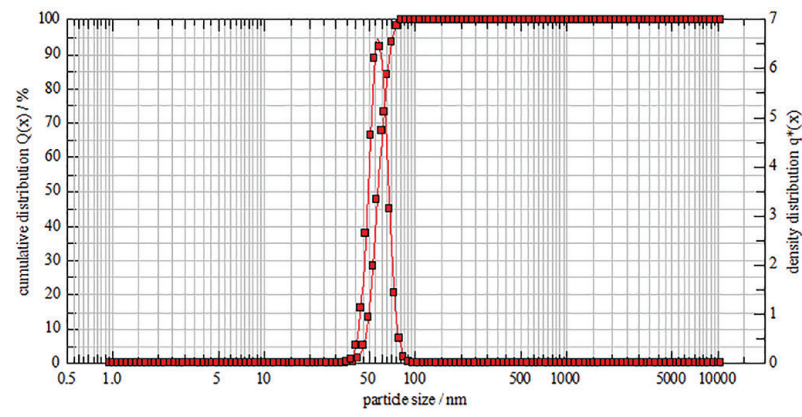

C:

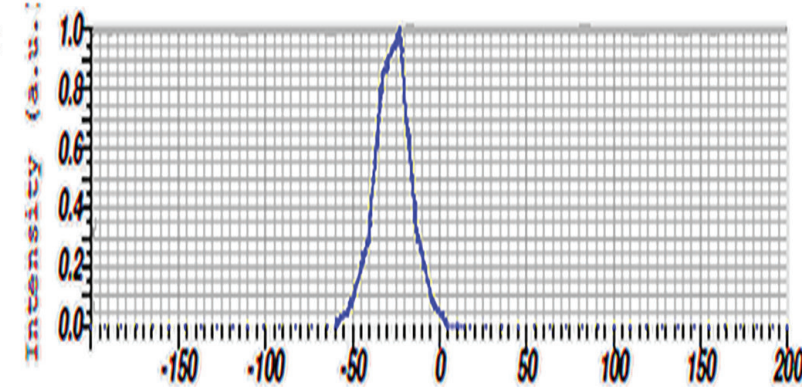

Zgta Podential(n)l)
B:

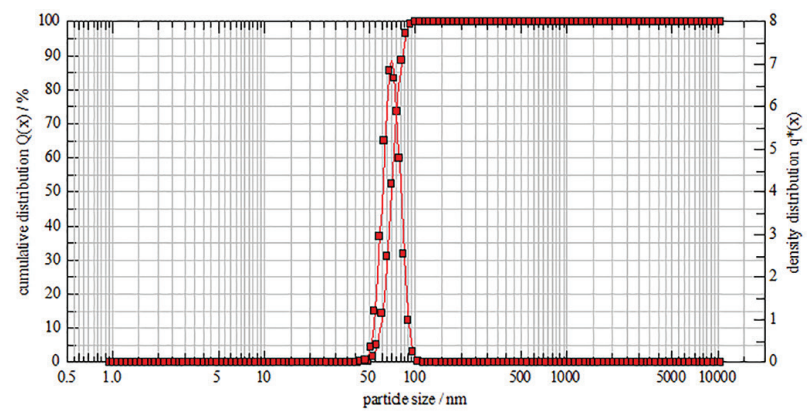

D:

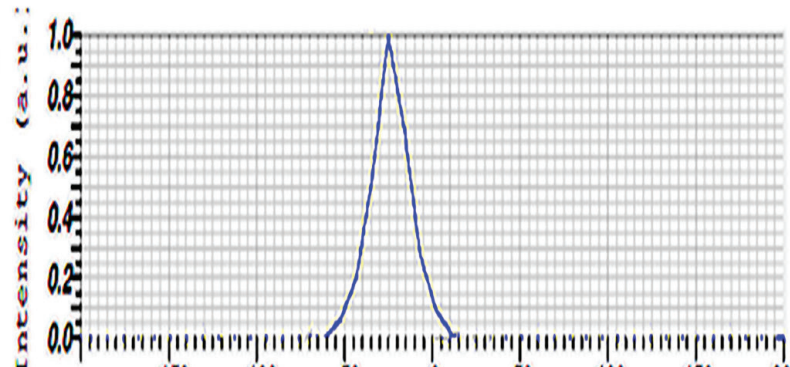

$\begin{array}{llllllll}.100 & .100 & .50 & 0 & 50 & 100 & 150 & 200\end{array}$

FIGURE 6 - (A) Droplet size distribution of optimized L-SMEDDS, (B) Droplet size distribution of optimized IR-SET, (C) Zeta potential of optimized L-SMEDD, (D) Zeta potential of optimized IR-SET. 
storing for $12 \mathrm{~h}$, it was observed that there was no sign of phase separation or drug precipitation. This suggests that the formulation (F3) was robust to dilution and change in diluents, thus maintaining their performance in vivo.

\section{Thermodynamic stability}

Thermodynamic stability studies helps in detection of detrimental alterations in formulations occurred over a significant period of time. Thermodynamic stability study avoids any metastable SMEDDS formulations. This instability basically arises from surfactant concentration. However, the optimized formula (F3) displayed good stability to all the three phases (heating cooling cycle/ freeze thaw cycle) and showed no sign of precipitation or phase separation even after centrifugation and were subjected for further characterization.

\section{Drug content}

There is a direct relationship between the drug incorporated and the lipophilicity of the drugs. Drug with higher lipophilicity can be encapsulated more than the other drugs. Drug content of L-SMEDDS was found to be $4.87 \pm 0.05 \mathrm{mg} / \mathrm{mL}$. So, drug content in percentage was calculated and the optimized formula (F3) had $97.43 \pm 0.30 \%$ of drug.

\section{Preparation of Solid NEB SMEDDS}

A free flowing powder was formulated by solidification of the optimized L-SMEDDS formulation (F3) by adsorption onto the selected carrier in particular ratio.

\section{Selection of adsorbent for S-SMEDDS}

The S-SMEDDS of individual adsorbent like Neusilin US2, Aerosil 200, microcrystalline cellulose PH102 and Lactose were prepared by adsorption onto the carrier technique. The angle of repose and quantity of adsorbent required was observed as a response. Among the different adsorbents (Table VIII), Neusilin US2 showed good flow property in ratio of 1:0.5 whereas Aerosil 200 was also required in same ratio but shown passable flow property. This can be explained by the fact that Neusilin US2 has a large specific area with high oil and water adsorption capacity (Qureshi, Mallikarjun, Kian, 2015) and therefore was selected as adsorbent.

\section{Evaluation of S-SMEDDS}

The S-SMEDDS prepared from optimized L-SMEDDS and Neusilin US2 were evaluated further for flow properties, SEM and XRD studies. The flow of S-SMEDDS was found to be good with $32.72 \pm 2.4$ angle of repose, $13.48 \pm 0.6$ carrs index and $1.15 \pm 0.02$ of hausners ratio. SEM micrograph of NEB (Figure 7A) showed smooth rectangular crystalline structures. While that of Neusilin US2 (Figure 7B) appeared to be spherical porous particles. Micrograph of solid SMEDDS (Figure 7C) showed liquid SMEDDS adsorbed onto the surface of Neusilin US2 particles. Crystalline characteristic structures of solid NEB were not detected in solid SMEDDS micrographs indicating that the drug must be present in an entirely dissolved state in the solid SMEDDS. X ray diffraction (XRD) study was performed to recognize various polymorphic forms of

TABLE VII - Stability studies of L-SMEDDS \& IR-SET

Storage condition $\left(40{ }^{\circ} \mathrm{C} / 75 \% \mathrm{RH}\right)$

\begin{tabular}{lcccc} 
Formulation & Time Period (days) & $\begin{array}{c}\text { Emulsification time } \\
(\mathbf{s e c})\end{array}$ & Drug content (\%) & $\begin{array}{c}\text { \% Cumulative drug } \\
\text { release in 10 min }\end{array}$ \\
\hline L-SMEDDS & & $16 \pm 1.52$ & $97.43 \pm 0.30$ & $73.44 \pm 1.14$ \\
(Batch F3) & 0 & $23 \pm 2.08$ & $96.81 \pm 0.30$ & $68.56 \pm 2.45$ \\
& 30 & $20 \pm 1.73$ & $96.59 \pm 0.47$ & $70.5 \pm 1.76$ \\
& 60 & $17 \pm 2.12$ & $95.3 \pm 0.72$ & $72.83 \pm 1.99$ \\
\hline IR-SET & Time Period (days) & Friability (\%) & Drug content (\%) & \% Cumulative drug \\
release in 10 min
\end{tabular}


TABLE VIII - Adsorbent selection for S-SMEDDS

\begin{tabular}{lcc}
\hline Adsorbent & Adsorbent required(ratio) & Angle of Repose \\
\hline Aerosil 200 & $1: 0.5$ & $41.81 \pm 1.18$ (passable) \\
Neusilin US2 & $1: 0.5$ & $32.72 \pm 2.4$ (good) \\
MCC PH102 & $1: 2$ & $43.15 \pm 1.55$ (passable) \\
Lactose & $1: 1.5$ & $37.32 \pm 2.17$ (fair) \\
\hline
\end{tabular}

the formulation and to detect the solvated and unsolvated state of the formulation. X-Ray diffraction studies of NEB (Figure 8A) showed sharp, distinct peaks at 5.9, $11.9^{\circ}$, $12.2^{\circ}, 16.3^{\circ}, 18.4^{\circ}, 21.4^{\circ}, 22.4^{\circ}$, and $25.67^{\circ}$ confirming that the pure drug is in the crystalline state. Whereas XRD graph of S-SMEDDS (Figure 8B) showed absence of NEB constructive peaks indicating conversion of NEB from crystalline to amorphous state in optimized formulation mainly because of solubilisation in the SMEDDS which was further adsorbed on to the solid carrier Neusilin US2 (Bakhle, Avari, 2015).
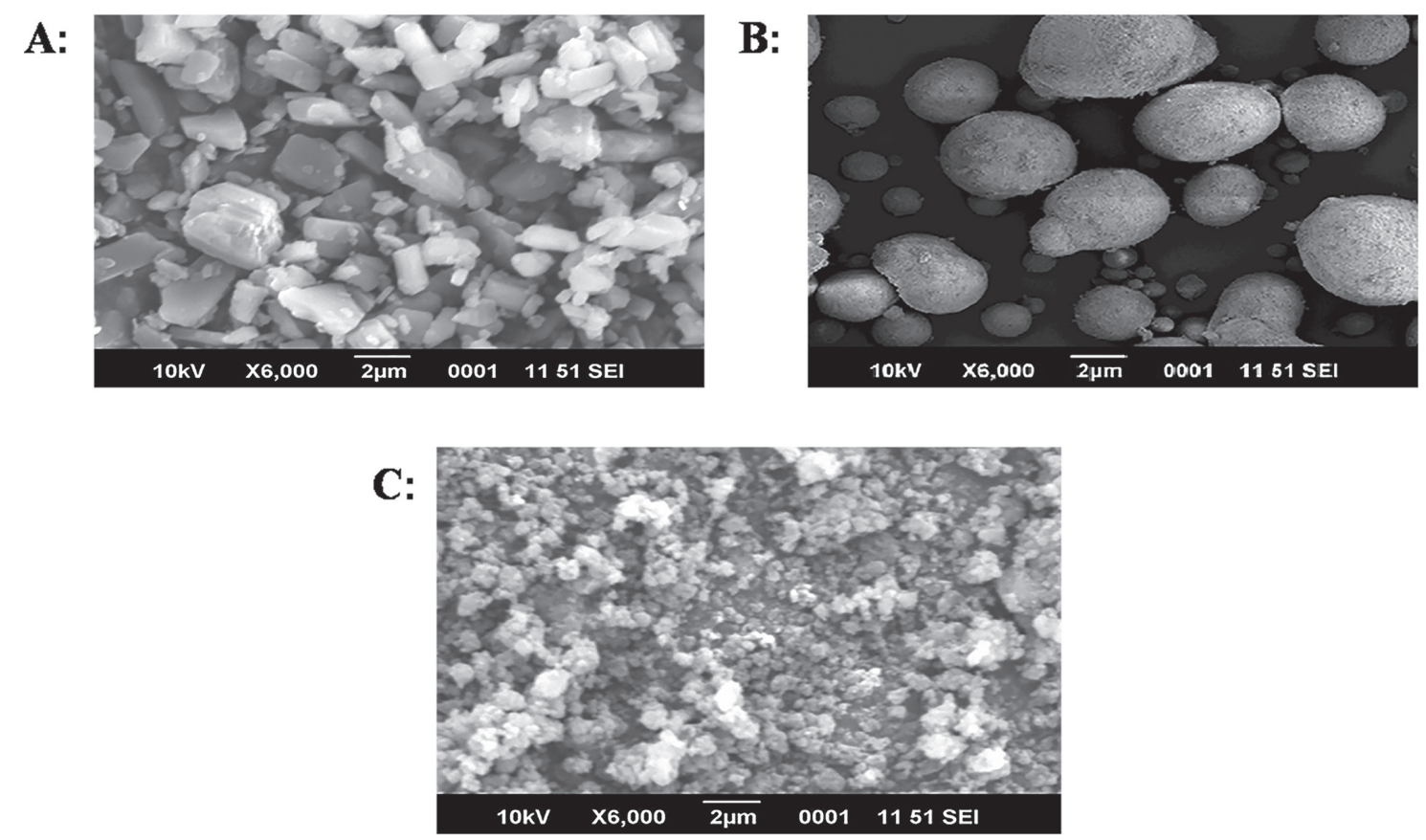

FIGURE 7 - SEM images of (A) Nebivolol HCl (B) Neusilin US2 (C) S-SMEDDS.
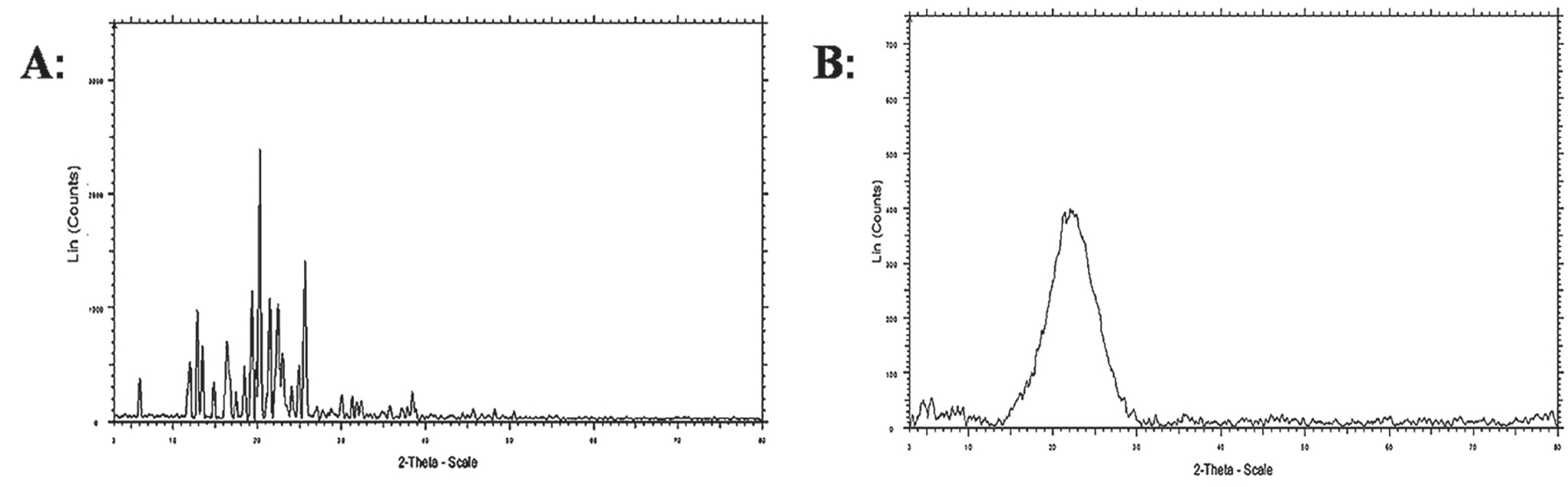

FIGURE 8 - XRD graph of (A) Nebivolol HCl (B) S-SMEDDS 


\section{Formulation of immediate release self emulsifying tablet (IR-SET)}

\section{Selection of super-disintegrant}

The criteria for selection of superdisintegrant depended on the minimum time required for disintegration. KOLLIDON CL showed minimum disintegration time of $245 \mathrm{~s}$. While Sodium starch glycollate and crosscarmellose sodium showed a disintegration time of about 419 and $367 \mathrm{~s}$ respectively. This could be attributed to the fact that KOLLIDON CL swells without any gel formation or crosslinking and thus was selected for IR SET preparation. In this study, the combined effect of binder (PVP K30) as well as super disintegrant (KOLLIDON CL) on the disintegration time, friability and hardness was determined. PVP K30 has a shorter wetting time because of its small particle size, moreover the uneven surface increases the area subjected to disintegration media which leads to a decrease in disintegration time (Hadel, 2014). While KOLLIDON CL improves tablet disintegration through its low particle size, which enhances tablet hardness with reduced friability (Maschke, Bang, Kolter, 2008). Also the efficacy of super disintegrant is very much affected by tablet size and hardness. Larger and harder tablets will have greater disintegration time, moreover lower values in hardness may cause increased friability which will affect the robustness of the tablet. Therefore, to ensure low disintegration time and friability, a satisfactory and optimal amount of the disintegrant and binder is important.

\section{Formulation and optimization of NEB IR-SET using experimental design}

The $3^{2}$ factorial design was constructed to optimize NEB IR-SET. The 9 experimental runs with actual values of independent variables and observed response parameters i.e. Disintegration time $\left(\mathrm{Y}_{1}\right)$ and Friability $\left(\mathrm{Y}_{2}\right)$ are given in Table IX. The optimized formula of NEB IR-SET contained L-SMEDDS loaded Neusilin US2 equivalent to $5 \mathrm{mg}$ of drug concentration with $5 \%$ of PVP K30 and KOLLIDON CL and 1\% magnesium stearate respectively. Very wide variation is observed in disintegration time and friability on changing the composition of formulation. The disintegration time and $\%$ friability ranged from $92 \pm 0.57 \mathrm{~s}$ to $169 \pm 1.15 \mathrm{~s}$ and $0.424 \pm 0.03 \%$ to $0.783 \pm 0.05 \%$, respectively (Table IX). Batch B9 shows minimum disintegration time $(92 \pm 0.57 \mathrm{~s})$ and minimum friability $(0.424 \pm 0.03 \%)$ and thus was selected for further processing.

Statistical analysis was carried out for all nine formulation batches by Design-Expert Software (Version
8.0.7.1, Stat-EaseInc., Minneapolis, MN). The effect of independent variables can be explained based upon the following equations:

(Disintegration time) $\mathrm{Y}_{1}=128.56-0.67 \mathrm{X}_{1}-30.17 \mathrm{X}_{2}$ (Friability) $\mathrm{Y}_{2}=0.59-0.15 \mathrm{X}_{1}-9.167 \mathrm{E}-003 \mathrm{X}_{2}$

Statistical significant coefficients $(\mathrm{P}=0.0034$ and $\mathrm{F}$ value $=16.87$ for $\mathrm{Y}_{1}$ and $\mathrm{P}=0.0019$ and $\mathrm{F}$ value $=21.13$ for $\mathrm{Y}_{2}$ ) were obtained for the model. From the $\mathrm{P}$ and $\mathrm{F}$ values, it could be concluded that the independent variables i.e. concentration of PVP K30 $\left(\mathrm{X}_{1}\right)$ and concentration of KOLLIDON CL $\left(\mathrm{X}_{2}\right)$ significantly affect the responses. The equations exhibit that as the concentration of PVP K30 $\left(\mathrm{X}_{1}\right)$ and KOLLIDON CL $\left(\mathrm{X}_{2}\right)$ increases, disintegration time $\left(\mathrm{Y}_{1}\right)$ and $\%$ friability values $\left(\mathrm{Y}_{2}\right)$ decreases.

The check point formulation (NEB IR-SET) was based on the optimum process variables and desired responses. The concentration of PVP K $30\left(\mathrm{X}_{1}\right)$ and KOLLIDON CL $\left(\mathrm{X}_{2}\right)$ chosen were $5 \%$ and $4.75 \%$ respectively. The disintegration time $\left(\mathrm{Y}_{1}\right)$ and friability $\left(\mathrm{Y}_{2}\right)$, predicted and experimental results are summarized in Table VI. The predicted value was equated with experimental value by calculating percentage error $(0.52 \%)$ which was found to be quite low, proved validity of generated model in predicting response. No significant difference was recorded between these two values, hence affirming the validity of generated model. 3D figures showed linear descending pattern for disintegration time and friability with increasing concentration of PVP K30 and KOLLIDON CL (Akhildevi et al., 2016) (Figure 9).

\section{Evaluation of NEB IR-SET}

The optimized IR-SETS (B9) were subjected to friability testing using Roche Friabilator and showed $0.424 \pm 0.03 \%$ friability. The friability is less than $1 \%$, which indicates that the tablets can handle the mechanical stress. Hardness was measured using Monsanto hardness tester which showed acceptable hardness in the range $2.5 \pm 0.11 \mathrm{~kg} / \mathrm{cm}^{2}$ to $2.8 \pm 0.29 \mathrm{~kg} / \mathrm{cm}^{2}$ indicating that the tablets can handle the mechanical stress (USP 36, 2013). While the hardness of the optimized batch (B9) was found to be $2.8 \pm 0.29 \mathrm{~kg} / \mathrm{cm}^{2}$. Disintegration time for nine batches ranged from $92 \pm 0.57 \mathrm{~s}$ to $169 \pm 1.15 \mathrm{~s}$ with disintegrating time of $92 \pm 0.57 \mathrm{~s}$ for batch B9, exhibiting that the tablet can disintegrate and release the self emulsifying system immediately. The low hardness values can be attributed to the fact that PVP K30 forms large number of pores in compressed tablet (Tuntikulwattana et al., 2010) on the 
TABLE IX - Optimization of IR-SET using Factorial design

\begin{tabular}{lcccc}
\hline Batches & $\begin{array}{c}\mathbf{X}_{1} \\
\text { Conc. of PVP K30 (\%) }\end{array}$ & $\begin{array}{c}\mathbf{X}_{2} \\
\text { Conc. of Kollidon CL (\%) }\end{array}$ & $\begin{array}{c}\mathbf{Y}_{1} \\
\text { Disintegration Time (sec) }\end{array}$ & $\begin{array}{c}\mathbf{Y}_{2} \\
\text { Friability (\%) }\end{array}$ \\
\hline B1 & 2.00 & 5.00 & $112 \pm 1.52$ & $0.783 \pm 0.05$ \\
B2 & 2.00 & 2.00 & $156 \pm 2.08$ & $0.756 \pm 0.03$ \\
B3 & 2.00 & 3.50 & $125 \pm 0.57$ & $0.735 \pm 0.04$ \\
B4 & 3.50 & 5.00 & $101 \pm 1.15$ & $0.532 \pm 0.07$ \\
B5 & 3.50 & 3.50 & $105 \pm 0.57$ & $0.558 \pm 0.05$ \\
B6 & 3.50 & 2.00 & $169 \pm 1.15$ & $0.515 \pm 0.05$ \\
B7 & 5.00 & 2.00 & $161 \pm 0.57$ & $0.523 \pm 0.03$ \\
B8 & 5.00 & 3.50 & $136 \pm 1.52$ & $0.443 \pm 0.04$ \\
B9 & $\mathbf{5 . 0 0}$ & $\mathbf{5 . 0 0}$ & $\mathbf{9 2} \pm \mathbf{0 . 5 7}$ & $\mathbf{0 . 4 2 4} \pm \mathbf{0 . 0 3}$ \\
\hline
\end{tabular}

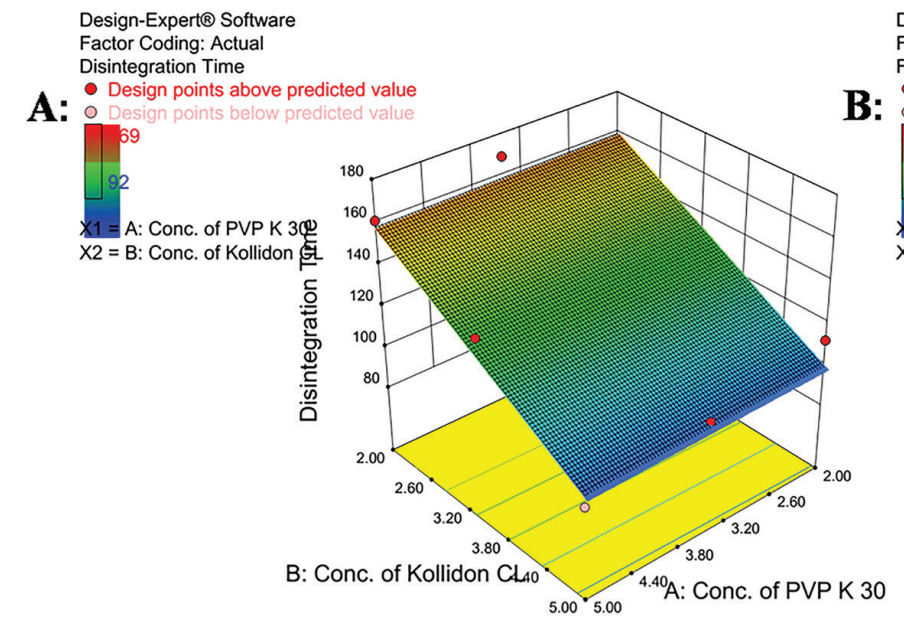
Design-Expert@ Software
Factor Coding: Actual

Friability

3. Design points above predicted value

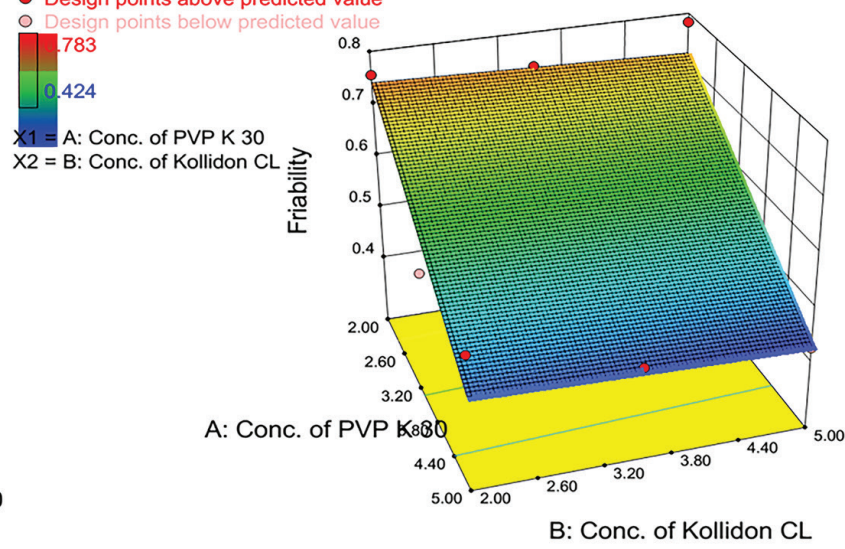

FIGURE 9 - Response surface plot for (A) Disintegration time (B) Friability.

other hand greater number of pores cause more water penetration thus leading to quick disintegration of tablets (Sharma, 2013; Hadel, 2014). The optimized IR-SETS after dilution showed clear appearance indicating single phase and the percent transmittance at wavelength of $650 \mathrm{~nm}$ was found out to be $98.67 \pm 0.73 \%$. Smaller the size of microemulsion droplet faster is the absorption. The optimized IR-SET showed $68.57 \mathrm{~nm}$ droplet size and 0.34 polydispersity index. Figure 6B shows the droplet size distribution of optimized formula. The zeta potential of optimized IR-SET was found to be $-25.3 \mathrm{mV}$, depicting the stable micro emulsion (Figure 6D).Drug content of optimized IR-SETS was found to be $4.81 \pm 0.03 \mathrm{mg} / \mathrm{mL}$ and percentage of drug content was calculated which had $96.33 \pm 0.15 \%$ of drug.

\section{In-vitro drug release}

The in vitro dissolution studies were carried out in order to ensure the quick release of the drug in the medium. The in vitro dissolution of the L-SMEDDS, IR-SET, Plain drug and Marketed tablets were performed in 900 $\mathrm{mL}$ of acid buffer $\mathrm{pH} 1.2$ using USP Type II dissolution apparatus with a paddle speed of $50 \mathrm{rpm}$. For L-SMEDDS and IR-SET formulations (Table X), it was observed that $73.44 \%$ and $61.28 \%$ of the drug released within first ten minutes of the dissolution time, respectively. This indicates that conversion of L-SMEDDS to IR-SET does not affect the drug release much more. Whereas, Plain drug and Marketed tablets, showed only $13.79 \%$ and $17.10 \%$ of the drug release, respectively. This clearly demonstrates the superior dissolution behavior of the developed SMEDDS as compared to Plain drug and Marketed tablets (Figure 10A). From the mathematical treatment of the in vitro release data of NEB from L-SMEDDS, IR-SET, Plain drug and Marketed tablet, the values of $\mathrm{R}^{2}$ (regression coefficient) has been obtained and presented in Table XI. From the regression coefficient value it was observed that drug release 
follows first order kinetics in L-SMEDDS and IR-SET systems while it followed higuchi model in Plain drug and Marketed tablet drug release. The data was further treated as per Korsmeyer's equation and slope (n) values obtained by these equations indicated that the drug release mechanism was Fickian diffusion in L-SMEDDS and IR-SET systems while it was Non-Fickian diffusion for Plain drug and Marketed tablet (Rao et al., 2013).

\section{Ex-vivo release profile}

Ex vivo studies were performed in order to determine the diffusion through biological membrane. After $2 \mathrm{~h}$ of diffusion, L-SMEDDS showed $97.56 \%$ of drug diffusion and IR-SET gave $93.24 \%$ of drug diffusion, while the dispersion of Plain drug and Marketed tablet gave $64.28 \%$ and $72.73 \%$ of drug diffusion respectively (Table XII). This indicates that diffusion of drug through the biological membrane was more when given in the form of SMEDDS formulations (Figure 10B). The augmentation in diffusion rate is due to formation of small droplets in nanometer range which enhanced the permeation of NEB because of the surfactant present, which reduced the interfacial tension within the formulation (Vijayanand, Patil, Reddy, 2015).

\section{Stability study}

Stability study results of the optimized batch L-SMEDDS (F3) and IR-SET(B9) are given in Table VII showing no significant changes during the study period of three months which further indicates that the formation is stable on storage (Kamble et al., 2012).

\section{CONCLUSION}

Self microemulsifying delivery system of NEB HCl

TABLE X - In-vitro drug release profile

\begin{tabular}{lcccc}
\hline \multirow{2}{*}{ Time (min) } & \multicolumn{4}{c}{ \% Cumulative drug release } \\
\cline { 2 - 5 } & L-SMEDDS & IR-SET & Plain drug & Marketed tablet \\
\hline 0 & $0 \pm 0$ & $0 \pm 0$ & $0 \pm 0$ & $0 \pm 0$ \\
10 & $\mathbf{7 3 . 4 4} \pm \mathbf{1 . 1 4}$ & $\mathbf{6 1 . 2 8} \pm \mathbf{2 . 3 9}$ & $\mathbf{1 3 . 7 9} \pm \mathbf{1 . 3 9}$ & $\mathbf{1 7 . 1 0} \pm \mathbf{1 . 1 0}$ \\
20 & $82.92 \pm 4.66$ & $74.65 \pm 2.99$ & $18.65 \pm 2.86$ & $21.20 \pm 1.27$ \\
30 & $92.93 \pm 3.14$ & $79.43 \pm 3.57$ & $21.84 \pm 1.64$ & $29.14 \pm 1.61$ \\
40 & $95.20 \pm 2.41$ & $86.48 \pm 1.24$ & $26.71 \pm 2.62$ & $33.73 \pm 1.28$ \\
50 & $98.42 \pm 3.75$ & $91.33 \pm 2.39$ & $28.71 \pm 3.93$ & $43.91 \pm 3.91$ \\
60 & $98.97 \pm 3.63$ & $96.19 \pm 4.99$ & $30.53 \pm 2.87$ & $44.62 \pm 2.98$ \\
70 & - & $96.89 \pm 4.05$ & $32.46 \pm 1.81$ & $46.35 \pm 1.63$ \\
80 & - & $98.51 \pm 4.87$ & $35.56 \pm 2.87$ & $47.78 \pm 2.56$ \\
90 & - & $98.38 \pm 4.80$ & $39.58 \pm 4.59$ & $48.85 \pm 2.31$ \\
\hline
\end{tabular}

A:

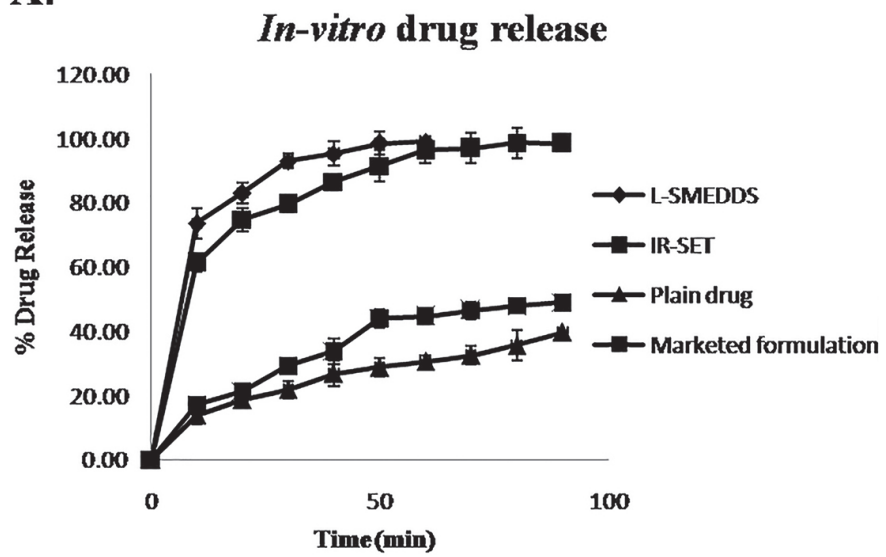

B:

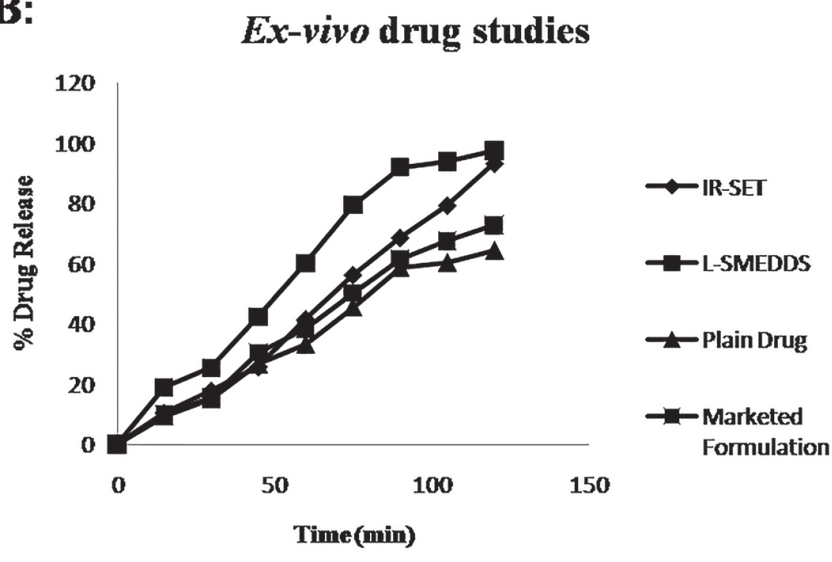

FIGURE 10 - In-vitro drug release profile and Ex-vivo diffusion studies of the L-SMEDDS, S-SMEDDS, Plain drug and Marketed formulation. 
TABLE XI - Drug release kinetics

\begin{tabular}{lccccc}
\hline \multirow{2}{*}{ Formulation code } & Zero order & First order & Higuchi model & \multicolumn{2}{c}{ Korsmeyer- Peppas model } \\
\cline { 2 - 6 } & $\mathrm{R}^{2}$ & $\mathbf{R}^{2}$ & $\mathbf{R}^{2}$ & $\mathrm{R}^{2}$ & $\mathrm{~N}$ \\
\hline L-SMEDDS & 0.870 & $\mathbf{0 . 9 8 4}$ & 0.937 & 0.971 & 0.175 \\
\hline IR-SET & 0.874 & $\mathbf{0 . 9 7 6}$ & 0.949 & 0.981 & 0.222 \\
Plain drug & 0.905 & 0.985 & $\mathbf{0 . 9 9 4}$ & 0.992 & 0.465 \\
Marketed tablet & 0.884 & 0.924 & $\mathbf{0 . 9 7 7}$ & 0.966 & 0.528 \\
\hline
\end{tabular}

TABLE XII - Ex-vivo diffusion studies

\begin{tabular}{lcccc}
\hline \multirow{2}{*}{ Time (min) } & \multicolumn{4}{c}{ \% Cumulative drug release } \\
\cline { 2 - 5 } & L-SMEDDS & IR-SETS & Plain drug & Marketed tablet \\
\hline 0 & 0 & 0 & 0 & 0 \\
15 & 18.95 & 10.38 & 9.48 & 9.98 \\
30 & 25.39 & 17.77 & 15.14 & 15.45 \\
45 & 42.34 & 25.71 & 26.57 & 30.35 \\
60 & 60.18 & 41.53 & 33.20 & 38.20 \\
75 & 79.53 & 56.24 & 45.48 & 50.22 \\
90 & 92.06 & 68.60 & 58.64 & 61.48 \\
105 & 93.88 & 79.31 & 60.23 & 67.36 \\
120 & $\mathbf{9 7 . 5 6}$ & $\mathbf{9 3 . 2 4}$ & $\mathbf{6 4 . 2 8}$ & $\mathbf{7 2 . 7 3}$ \\
\hline
\end{tabular}

were successfully designed, formulated and optimized as L-SMEDDS and IR-SET using experimental design. Optimized L-SMEDDS contains Kollisolv GTA as oil, Tween 80 as surfactant and Propylene glycol as cosurfactant in the ratio of $20 \%: 26.66 \%: 53.34 \% \mathrm{w} / \mathrm{W}$ which gave lower droplet size (55.98 nm), PDI (0.37), emulsification time $(16 \pm 1.52 \mathrm{~s})$, zeta potential $(-26.8 \mathrm{mV})$ and drug content $(97.43 \pm 0.30 \%)$. The optimized L-SMEDDS, batch F3 were successfully converted into a free flowing powder(S-SMEDDS) using Neusilin US2 which was directly compressed into self emulsifying immediate release tablets (IR-SET). DSC and XRD data of the solid SMEDDS powder established that the drug was completely solubilized in the lipid excipients and /or the crystalline form of the drug was converted to molecular/ amorphous one. Optimized IR-SETS contains PVP K30 as binder, KOLLIDON CL as super disintegrant in the ratio 5\%:5\% and showed disintegration time $(92 \pm 0.57 \mathrm{~s})$, friability $(0.424 \pm 0.03 \%)$, hardness $(2.8 \pm 0.29 \mathrm{~kg} /$ $\left.\mathrm{cm}^{2}\right)$, droplet size $(68.57 \mathrm{~nm})$, PDI $(0.34)$, zeta potential $(-25.3 \mathrm{mV})$ and drug content $(96.33 \pm 0.15 \%)$. Also the in vitro dissolution performance was similar for L-SMEDDS and IR-SET showing $73.44 \%$ and $61.28 \%$ drug release in 10 minutes, respectively which was significantly higher than the marketed tablet and plain drug. Stability studies showed absence of chemical and physical changes over a period of 90 days. Thus NEB can be successfully designed and formulated as L-SMEDDS and subsequently into S-SMEDDS (IR-SET) with drastically improved release characteristics.

\section{ACKNOWLEDGEMENT}

The authors are thankful to AICTE, New Delhi for rendering financial assistance. The authors are grateful to all manufacturers/suppliers for providing excipients free of cost for this study. Authors would also like to thank SAIF, Kochi, India for providing the SEM and XRD data. We are grateful to Head, Department of Pharmaceutical Sciences, R.T.M. Nagpur University for providing facilities.

\section{DECLARATIONS OF INTERESTS}

The authors report no conflict of interest to anybody.

\section{REFERENCES}

Ahammad AK, Pani NR. Development, optimization and characterization of self emulsified tablet of simvastatin. Biopharm J. 2016;2(2):46-54. 
Akhildevi D, Nappinai M, Jerad SA, Amudha P, Vetrichelvan T. Design and evaluation of SEDDS of glibenclamide by optimization technique using response surface methodology. IJIPSR. 2016;4(7):709-731.

Bakhle SS, Avari J G. Formulation and evaluation of solid self- microemulasifying drug delivery system for improved oral delivery of olmesartan medoxomil. IJPSR. 2015;6(8):32853298.

BASF. Technical information. [cited November 2012]. Available from: https://products.basf.com/documents/ pim;save/en/8805242907093.Kollisolv\%C2\%AEGTA-\%20 Technical\%20Information.pdf.

BASF. Technical information. [citad June 2013]. Available from: https://industries.basf.com/bin/bws/documentDownload. en. 8805243202005 .

Furniss BS, Hannaford AJ, Smith PWG, Tatchell AR. Practical Organic Chemistry, $5^{\text {th }}$ edition. New York: Pearson; 2008, 236240.

Gurram AK, Deshpande PB, Kar SS, Nayak UY, Udupa N, Reddy MS. Role of components in the formation of selfmicroemulsifying drug delivery systems. Indian J Pharm Sci. 2015;77(3):249-257.

Hadel AE. Development and evaluation of fast disintegrating extended release tablets containing antihypertensive drug. Int J Pharm Pharm Sci. 2014;6(6):165-174.

Jaiswal P, Aggarwal G, Sasidharan LH, Singh K. Development of self-microemulsifying drug delivery system and solid-selfmicroemulsifying drug delivery system of telmisartan. Int $\mathbf{J}$ Pharm Investig. 2014;4(4):195-206.

Jana U, Mohanty AK, Manna PK, Mohanta GP. Preparation and characterization of nebivolol nanoparticlesusing Eudragit ${ }^{\circledR}$ RS100. Colloids Surf B Biointerfaces. 2014;113:269-275.

Kamble MS, Borwandkar, VG, Mane SS, Mane OR, Aute PP, Chaudhari PD. Formulation and evaluation of lipid based nanoemulsion of glimepiride using self-emulsifying technology. Indo Am J Pharm Res. 2012;2(9):1111-25.

Khalaf J, Ardelean S, Drăgănescu1 D, Ardelean M, Lupuleasa D. Delivery of nebivolol hydrochloride from immediate release tablets. Studia Univ. 2015;25(1):47-50.
Khan F, Islam MS, Roni MA, Jalil R. Systematic Development of self-emulsifying drug delivery systems of atorvastatin with improved bioavailability potential. Sci Pharm. 2012;80:10271043.

Laddha P, Suthar V, Butani S. Development and optimization of self microemulsifying drug delivery of domperidone. Braz J Pharm Sci. 2014;50(1):92-100.

Madan JR, Sudarshan B, Kadam VS, Kamal D. Formulation and development of self-microemulaifying drug delivery system of pioglitazone hydrochloride. Asian J Pharm. 2014;8(1):27-34.

Mahajan HD, Shaikh T, Baviskar D, Wagh RD. Design and development of solid self-microemulsifying drug delivery system of fenofibrate. Int J Pharm Pharm Sci. 2011;3(4):163166.

Maschke A, Bang F, Kolter K. Effect of crosspovidone particle size on tablet properties prepared via wet granulation. PBP World Meeting. April 2008; Barcelona. Spain G-EMP/MD 217. p 7-10.

Narkhede RS, Gujar KN, Gambhire VM. Design and evaluation of self-nanoemulsifying drug delivery systems for nebivolol Hydrochloride. Asian J Pharm. 2014;4(2):200-209.

Patela MJ, Patela NM, Patel RB, Patel RP. Formulation and evaluation of self-microemulsifying drug delivery system of lovastatin. Asian J Pharm Sci. 2010;5(6):266-275.

Pandey V, Kohli S. SMEDDS of pioglitazone: Formulation, in-vitro evaluation and stability Studies. Future J Pharm Sci. 2017;3:53-59.

Pimple SS, Yeole SE, Chaudhari PD. Formulation and evaluation of self micro emulsifying drug delivery system for poorly water soluble drug risperidone. Int J Pharm Sci Rev Res. 2013;23(1):155-162.

Porter CJH, Pouton CW, Cuine JF, Charman WN. Enhancing intestinal drug solubilisation using lipid-based delivery systems. Adv Drug Deliv Rev. 2008;60(6):673-691.

Prajapati ST, Joshi HA, Patel CN. Preparation and characterization of self-microemulsifying drug delivery system of olmesartan medoxomil for bioavailability improvement. J Pharm. 2013;2013:728425. 
Pravala K, Nagabandi VN, Ajmeera. Enhancement of bioavailability of nebivolol hydrochloride through liquisolid formulations: In Vitro and In Vivo evaluation. Schol Res Library Pharm Lettre. 2013;5(6):151-163.

Qureshi MH, Mallikarjun C, Kian WG. Enhancement of solubility and therapeutic potential of poorly soluble lovastatin by SMEDDS formulation adsorbed on directly compressed spray dried magnesium aluminometasilicate liquid loadable tablets: A study in diet induced hyperlipidemic rabbits. Asian J Pharml Sci. 2015;10(1):40-56.

Rahman MA, Hussain A, Hussain MS, Mirza MA, Iqbal Z. Role of excipients in successful development of self-emulsifying/ microemulsifying drug delivery system (SEDDS/SMEDDS). Drug Dev Ind Pharm. 2013;39(1):1-19.

Rao BP, Durgaprasad K, Ramesh S, Rajarajan B, Sreedhar C. Formulation and evaluation of SMEDDS with capmul MCM for enhanced dissolution rate of valsartan. J Pharm Sci. 2013;3(2):33-40.

Shah I, Bhatt S, Yadav A. Enhancement of solubility and dissolution of nebivolol by solid dispersion technique. Int $\mathrm{J}$ Pharm Pharm Sci. 2014;6(7):566-571.

Sharma D. Formulation development and evaluation of fast disintegrating tablets of salbutamol sulphate for respiratory disorders. ISRN Pharm. 2013;10(1155):1-8.
Thadkala K, Sailu C, Aukunuru J. Formulation, optimization and evaluation of oral nanosuspension tablets of nebivolol hydrochloride for enhancement of dissoluton rate. Pharm Lettre. 2015;7(3):71-84.

Thula KC, Patel DC, Maheshwari DG. Development and validation of first order derivative uv spectrophotometric method for simultaneous estimation of nebivolol and cilnidipine in pharmaceutical formulation. Int J Pharm Sci Rev Res. 2015;31(1):243-247.

Tuntikulwattana S, Mitrevej A, Kerdcharoen T, Williams DB, Sinchaipanid N. Development and optimization of micro/ nanoporous osmotic pump tablets. AAPS PharmSciTech. 2010;11(2):924-93.

United State Pharmacopoeia USP 36, NF 31. The United States Pharmacopeias Convention 1261. Rockville, MD; 2013.p.25659.

Vijayanand P, Patil JS, Reddy MV. Formulation characterization and in-vitro/in-vivo evaluation of orodispersible tablets of Nebivolol HCl. Pelagia Res Library Pharm Sinica. 2015;6(4):103-114.

Zanchetta B, Chaud MV, Santana MHA. Self-emulsifying drug delivery systems (sedds) in pharmaceutical development. J Adv Chem Eng. 2015;5(3):1-7.

Received for publication on $08^{\text {th }}$ February 2018 Accepted for publication on $13^{\text {th }}$ November 2018 